\title{
Los retos de la seguridad energética y el cambio climático: hacia una economía europea sostenible
}

\author{
The Challenges of Energy Security and Climate Change: \\ towards a Sustainable European Economy
}

Asier García Lupiola

Universidad del País Vasco (UPV-EHU)

asier.garcialupiola@ehu.eus

Sumario: I. Introducción.-II. Configuración y desarrollo de las diferentes herramientas europeas a favor del desarrollo sostenible. 1. La política de medio ambiente y la estrategia climática. 2. La política energética. 3. El Tratado de Lisboa y la Estrategia Europa 2020. 4. La acción climática y su vinculación con la energía.-III. Los instrumentos más recientes de la UE para hacer frente a los retos de la seguridad energética y el cambio climático. 1. El Marco clima y energía para 2030. 2. La Estrategia de seguridad energética. 3 La Unión de la Energía. 4. El Acuerdo de París. 5. El paquete energía limpia.-IV. Conclusiones

Resumen: El desarrollo sostenible se configura como objetivo general de la integración europea, de manera que el crecimiento económico sea compatible con la protección del medio ambiente. Desde hace ya varios años el mayor reto en esta materia es la lucha contra el cambio climático, al que se ha sumado, por su creciente gravedad, la seguridad de abastecimiento energético. Se trata de dos desafíos que actualmente se encuentran vinculados por las herramientas que se proponen desde la UE para afrontarlos, principalmente, el impulso de las energías renovables y la eficiencia energética.

Palabras clave: Unión Europea, desarrollo sostenible, acción climática, política energética

Abstract: Sustainable development is a general objective of European integration, that is, that economic growth is compatible with the protection of the environment. For several years now, the greatest challenge in this area has been the fight against climate change, to which the security of energy supply has been added due to its growing seriousness. These are two challenges that are currently linked by the tools proposed by the EU to address them, mainly, the promotion of renewable energy and energy efficiency.

Keywords: European Unión, sustainable development, climate action, energy policy

Cuadernos Europeos de Deusto 


\section{Introducción}

El artículo 3.3 del Tratado de la Unión Europea (TUE) establece que la Unión «Obrará en pro del desarrollo sostenible de Europa basado en un crecimiento económico equilibrado y en la estabilidad de los precios, en una economía social de mercado altamente competitiva, tendente al pleno empleo y al progreso social, y en un nivel elevado de protección y mejora de la calidad del medio ambiente». Es decir, el logro de una economía sostenible es uno de los objetivos generales del proceso de integración europea y así se recoge en la normativa fundamental que lo rige.

Desde sus fundamentos legales, la Unión Europea (UE) está haciendo suya una de las mayores preocupaciones de la sociedad en la actualidad como es la protección del medio ambiente, una preocupación que crece exponencialmente ante la relevancia de los efectos del cambio climático. No obstante, lo cierto es que los Tratados constitutivos de las Comunidades Europeas (CCEE) no establecieron ninguna normativa de protección medioambiental, si bien gracias a las diferentes reformas habidas en los mismos acabó recogido en los textos jurídicos fundamentales de la UE. De esta manera, el desarrollo sostenible quedó determinado en el seno del Derecho Originario europeo como fin vinculante para todos los Estados miembros de la Unión.

Tampoco la política energética era recogida en los Tratados fundacionales ni lo ha sido durante la mayoría de las reformas de los mismos. Al tratarse de una política considerada por los países como cuestión estratégica y de interés nacional no se ha desarrollado como política europea hasta época reciente, y ello a pesar de que si algo tienen en común los Estados miembros en esta materia es la dependencia energética. Ahora bien, resulta llamativo que cuando la UE ha puesto en marcha una política energética, ésta ha servido como herramienta para la protección medioambiental y, especialmente, para lograr una mayor eficacia en la lucha contra el cambio climático. En buena medida, se ha seguido la vía de impulso de las energías renovables, la cual ha servido, al mismo tiempo, para tratar de atender el otro gran reto al que se enfrenta Europa como es la seguridad de abastecimiento energético.

Por lo tanto, en la actualidad el objetivo de desarrollo sostenible pasa por hacer frente tanto al cambio climático como a la dependencia energética, dado que una de las vías para asegurar el abastecimiento energético es el impulso de las energías renovables, precisamente, una de las grandes herramientas para luchar contra las consecuencias del cambio climático. El objetivo del presente texto consiste en analizar los diferentes instrumentos de los que se dota la UE para encarar dichos retos. De este modo, en la primera de las dos partes en que se divide, se realiza un recorrido histórico de 
las iniciativas y herramientas desarrolladas en el seno del proceso de integración europea para alcanzar el objetivo del desarrollo sostenible y, específicamente, afrontar los desafíos del cambio climático y la seguridad energética. En la segunda se analizan los mecanismos más actuales, recientemente diseñados y aprobados - alguno, aún en trámite-, que determinan el camino que seguirá la UE durante los próximos años.

Como se verá, la progresiva configuración de la política medioambiental europea, la estrategia climática y la política energética, han llevado a la UE a establecer una serie de elementos fundamentales - en el Derecho Originario y en los programas y estrategias que determinan su desarrollo-, que en la actualidad la posicionan adecuadamente para atender los objetivos $\mathrm{y}$ retos mencionados.

\section{Configuración y desarrollo de las diferentes herramientas europeas a favor del desarrollo sostenible}

\section{La política de medio ambiente y la estrategia climática}

Los orígenes de la política europea de medio ambiente se sitúan en los comienzos de la década de 1970, dado que los Tratados fundacionales de las CCEE no regularon el establecimiento de la misma. La Comisión adoptó en 1971 el primer documento sobre esta materia ante la necesidad de tener presente el medio ambiente al objeto de regular adecuadamente el desarrollo del Mercado Común y evitar obstáculos a la libre circulación de mercancías ${ }^{1}$. Como se ve, «la configuración de un bloque comercial (...) formado por países con distintos niveles de calidad medioambiental, llevó a plantearse a los Estados miembros la conveniencia de adoptar una perspectiva supranacional en el diseño de las grandes líneas a seguir» ${ }^{2}$.

El desarrollo de la política medioambiental comenzó con la puesta en marcha de los Programas de Acción sobre Medio Ambiente (PMA). Los dos primeros, adoptados por el Consejo en 1973 y en 1976, tuvieron que enfrentarse a un contexto adverso marcado por la crisis del petróleo y la consiguiente recesión económica. Ambos «pusieron los pilares para la defensa de los intereses ambientales en la Comunidad y fijaron como gran objetivo la utilización racional de los recursos naturales compatible con el de-

${ }^{1}$ Comisión Europea, Comunicación de 22 de julio de 1971, Première communication sur la politique de la Communauté en matière de l'environnement, Sec. (71) 26/6.

${ }^{2}$ Rafael Muñoz Bustillo y Rafael Bonete, Introducción a la Unión Europea: un análisis desde la economía (Madrid: Alianza, 2002), 295. 
sarrollo económico» ${ }^{3}$. El Tercer PMA, adoptado por el Consejo en 1983, aportaba una novedad significativa consistente en que formuló una estrategia global de protección medioambiental para su integración en todas las políticas comunitarias, al constatarse que las consideraciones ambientales incidían sobre determinados ámbitos de actuación, como agricultura, industria, transportes o energía.

Con el objeto de poner en marcha el mercado interior de la Comunidad Europea (ya en singular, CE), el Acta Única Europea (AUE) de 1986 introdujo en el ámbito comunitario la regulación de materias estructuradas como nuevas políticas, tal y como sucedió con el medio ambiente ${ }^{4}$. El AUE «instaló la conservación del medio ambiente en el derecho primario de la CE y aludió a su condición inherente al desarrollo económico y social, la calidad de vida y la sostenibilidad de otras políticas europeas» ${ }^{5}$, como el comercio, la agricultura, la investigación o la energía.

Poco después de la entrada en vigor del AUE, en octubre de 1987 el Consejo aprobaba el Cuarto PMA, que continuó con la línea iniciada con el Tercer Programa, a saber, la integración en otras políticas comunitarias de los aspectos medioambientales ${ }^{6}$. En diciembre de 1992 el Consejo aprobó el Quinto PMA, alargando su vigencia hasta un período de diez años. Su objetivo general era orientar progresivamente el modelo de crecimiento europeo hacia el desarrollo sostenible, mediante el cambio de las pautas de producción y consumo, para lo que establecía objetivos específicos en cinco sectores. A destacar los referente a la energía: mejora de la eficacia energética, reducción del consumo de combustibles fósiles y promoción de las energías renovables.

Los Tratados modificativos de Maastricht de 1992 y de Ámsterdam de 1997 concretaron los fundamentos de la política medioambiental europea (el Tratado de Niza no aportó novedades en este ámbito). De este modo, el Derecho Originario europeo pasó a subrayar el desarrollo sostenible como una de las principales metas de la Unión, dejándolo establecido definitiva-

${ }^{3}$ Eduardo Cuenca García, Economía de la Unión Europea (Madrid: Pearson-Prentice Hall, 2007), 419.

${ }^{4}$ Se buscaba una respuesta ante los retos que planteaba la propia ciudadanía, cuya presión a favor de la protección medioambiental crecía ante los desastres ecológicos cada vez mayores y en especial ante la tragedia de Chernóbil. David M. Wood y Birol A. Yesilada, The Emerging European Union (Nueva York: Pearson Longman, 2006), 172.

5 José Antonio Nieto Solís, La Unión Europea. Una nueva etapa en la integración económica de Europa, (Madrid: Pirámide, 2005), 217.

${ }^{6}$ El Cuarto PMA posibilitó, además, la creación de los instrumentos adecuados para el desarrollo de la política ambiental, como la Agencia Europea de Medio Ambiente en 1990 (puesta en marcha en 1994) y el instrumento financiero específico para la protección del medio ambiente LIFE en 1992. 
mente como objetivo del proceso de integración europea y no exclusivamente de la política de medio ambiente ${ }^{7}$.

En marzo de 2000 el Consejo Europeo aprobó la conocida como Estrategia de Lisboa, un plan global que tenía por objetivo convertir Europa en la economía del conocimiento más competitiva y dinámica del mundo para 2010. La dimensión ambiental fue incorporada a los objetivos de la misma posteriormente, estableciendo la Estrategia Europea para el Desarrollo Sostenible ${ }^{8}$. En ella se subrayaba la importancia que adquiría el que se consideraba ya el mayor reto medioambiental: la lucha contra el cambio climático. A este respecto, la Comisión había propuesto poner en marcha una estructura destinada a identificar y preparar la ejecución de las medidas de lucha contra el cambio climático ${ }^{9}$. Y siguió quedando patente su importancia en el Sexto PMA, aprobado en julio de $2002^{10}$. En efecto, entre los cuatro ámbitos de actuación determinados por el programa, destaca el cambio climático, determinándose como meta específica alcanzar los objetivos del Protocolo de Kioto.

Precisamente, la UE había aprobado poco antes el Protocolo de Kioto ${ }^{11}$. Para el primer período de vigencia previsto (2008-2012) se estableció un compromiso general de reducción de emisiones de gases de efecto invernadero (GEI) para los países desarrollados del 5 \% respecto de las de 1990. Dentro del mismo, la Unión aceptó un objetivo específico de reducción del $8 \%$, estableciéndose para cada Estado miembro un margen distinto en función de diversas variables económicas y medioambientales ${ }^{12}$.

En enero de 2007 iba a establecerse de manera permanente la vinculación de los ámbitos medioambiental, principalmente en lo referido a la lu-

7 Wood y Yesilada, The Emerging..., 172.

${ }^{8}$ Consejo Europeo de Gotemburgo de 15 y 16 de junio de 2001 - Conclusiones de la Presidencia, SN 2001/1/01 REV 1.

${ }^{9}$ Comisión Europea, Comunicación de 8 de marzo de 2000, Sobre políticas y medidas de la UE para reducir las emisiones de gases de efecto invernadero, «Hacia un Programa Europeo sobre el Cambio Climático» (PECC), COM (2000) 88 final.

10 Decisión n. ${ }^{\circ}$ 1600/2002/CE del Parlamento Europeo y del Consejo, de 22 de julio de 2002, por el que se establece el Sexto Programa de Acción sobre Medio Ambiente (DOCE L 242/1, de 10 de septiembre de 2002).

11 Decisión 2002/358/CE del Consejo, de 25 de abril de 2002, relativa a la aprobación, en nombre de la Unión Europea, del Protocolo de Kioto de la Convención Marco de las Naciones Unidas sobre el Cambio Climático, y al cumplimiento conjunto de los compromisos contraídos con arreglo al mismo (DOUE L 207/15, de 4 de septiembre de 2015)

12 Según el Anexo B del Protocolo de Kioto, junto a la entonces UE-15, Bulgaria, Rep. Checa, Eslovaquia, Eslovenia, Estonia, Letonia, Liechtenstein, Lituania, Mónaco, Rumanía y Suiza adoptaron el compromiso de reducción de emisiones del $8 \%$; EEUU, el $7 \%$; Canadá, Hungría, Japón y Polonia, el $6 \%$; y Croacia, el $5 \%$. Nueva Zelanda, Rusia y Ucrania se comprometían a no aumentar sus emisiones, mientras que tres países podían aumentarlas: Noruega, el $1 \%$; Australia, el $8 \%$; e Islandia, el $10 \%$. 
cha contra el cambio climático, y energético. En efecto, la Comisión concretó la estrategia europea de lucha contra el cambio climático ${ }^{13}$, al tiempo que dio a conocer su propuesta ante los retos que se plantean en materia energética en Europa, en particular el cambio climático y la seguridad de abastecimiento de la Unión ${ }^{14}$. Ambas fueron adoptadas por el Consejo Europeo ${ }^{15}$ y definirían la reforma que tendría lugar con el Tratado de Lisboa.

De este modo, se fijó como objetivo unilateral de la UE la reducción de las emisiones de GEI en el $20 \%$ respecto de 1990 para el año 2020. El Consejo Europeo consideró que los países desarrollados deberían comprometerse, en el marco de un acuerdo internacional, a reducir colectivamente sus emisiones en un $30 \%$ hasta 2020 y entre un $60 \%$ y un $80 \%$ hasta 2050 . En el caso de que se concluya dicho acuerdo, la UE se fijaría como objetivo la reducción de emisiones en un $30 \%$ hasta 2020. En cuanto al ámbito energético, vista su relevancia en la lucha contra el cambio climático, el Consejo Europeo fijó los objetivos a lograr en el año 2020 por la UE: aumentar la eficiencia energética con el fin de ahorrar un $20 \%$ del consumo energético; llevar al $20 \%$ el porcentaje representado por las energías renovables en el consumo energético total; elevar al $10 \%$ el porcentaje representado por los biocarburantes en el transporte.

\section{La política energética}

La Declaración Schuman de 1950 impulsaba la puesta en común de las producciones de carbón y de acero como objetivo para garantizar el desarrollo económico europeo. Teniendo en cuenta que entonces el carbón suministraba el $90 \%$ de la energía en Europa, se ponía de manifiesto que «la cuestión energética y su vínculo con la prosperidad estaban presentes en las preocupaciones iniciales de los líderes políticos europeos» ${ }^{16}$. Sin embargo, con la excepción inicial del carbón y de la energía nuclear, la integración europea en el ámbito energético no ha sido una prioridad por parte de los Estados miembros hasta época reciente. Ello se debe a que «la seguridad energética se considera en todos los países un factor estra-

13 Comisión Europea, Comunicación de 10 de enero de 2007, Limitar el calentamiento mundial a $2{ }^{\circ} \mathrm{C}$-Medidas necesarias hasta 2020 y después, COM (2007) 2 final.

${ }^{14}$ Comisión Europea, Comunicación de 10 de enero de 2007, Una política energética para Europa, COM (2007) 1 final.

15 Consejo Europeo de Bruselas de 8 y 9 de marzo de 2007 - Conclusiones de la Presidencia, 7224/1/07 REV1.

${ }^{16}$ Sagrario Morán Blanco, Seguridad Energética y Medio Ambiente. Dos caras de una misma moneda. Especial referencia a la Unión Europea (Cizur Menor, Navarra: Thomson Reuters Aranzadi, 2015), 132. 
tégico fundamental que debe mantenerse esencialmente bajo el control de las instituciones políticas de cada Estado», lo que explica «las reticencias a la cesión de soberanía en materia de seguridad energética a instituciones supranacionales» ${ }^{17}$.

Los primeros pasos en la estructuración de una cooperación energética entre los Estados miembros tuvieron lugar tras la entrada en vigor de los Tratados constitutivos de las CCEE, con las primeras propuestas para una unidad de mercado en este ámbito. Entre los objetivos establecidos para la futura política energética europea se encontraban el suministro barato, la seguridad de suministro, el desarrollo de productos sustitutivos y la estabilidad del suministro ${ }^{18}$. Se aprecia claramente que la idea de sostenibilidad no era tenida en cuenta.

Las consecuencias de la crisis del petróleo de 1973 pusieron de relieve la vulnerabilidad de Europa por su dependencia energética del exterior y la falta de solidaridad entre los países miembros, lo que requería fortalecer la cooperación en esta materia. La Comisión presentó una propuesta que incidía en el objetivo de la seguridad en el suministro y la estabilidad de los precios, apostando además por el fomento de la energía nuclear ${ }^{19}$. A pesar de que la situación parecía empujar a la puesta en marcha de una política energética común, no hubo un desarrollo de la misma dado el obstáculo insalvable que supuso «el celo con que los gobiernos se aferraron a mantener el control sobre el sector de la energía, dadas las ramificaciones de todo orden que tienen las políticas concernientes a la misma» ${ }^{20}$.

Tras la segunda oleada de la crisis se puso en marcha un plan para lograr un uso racional de la energía, al objeto de mantener el suministro energético y de hacerlo con un coste relativamente barato, condiciones indispensables para el sostenimiento del modelo económico-social europeo ${ }^{21}$. Aunque se seguía incidiendo en el consumo de carbón y en el impulso de programas nucleares, se apostó también, aunque de manera tímida, por las energías renovables y se aconsejó actuar en materia de I+D con respecto a las mismas. Ahora bien, debe subrayarse que la toma en consideración de

17 Claudio Aranzadi, «Energía y Geoestrategia: Introducción», Cuadernos de Estrategia, n. ${ }^{\circ} 166$ (2014): 35.

${ }_{18}$ Comisión Europea, Comunicación de 18 de diciembre de 1968, First guidelines for a Community energy policy, COM (68) 1040.

${ }^{19}$ Comisión Europea, Comunicación de 26 de junio de 1974, Towards a new energy policy strategy for the European Community, COM (74) 550 final/2.

${ }^{20}$ Kepa Sodupe y Eduardo Benito, «Los problemas energéticos en la Unión Europea a la luz del tratado sobre la Carta de la Energía», Anuario español de derecho internacional, n. ${ }^{\circ} 16$ (2000): 422.

${ }^{21}$ Comisión Europea, Comunicación de 2 de octubre de 1981, The development of an energy strategy for the Community, COM (81) 540. 
las energías renovables «no encuentra su fundamento aún en motivos ambientales sino en razones de seguridad del suministro mediante la sustitución del petróleo» 22 .

Dicha actitud comenzó a variar cuando a finales de la década de los años 80 se reconoció que la eficiencia energética y el uso de energías renovables contribuyen de manera importante a la reducción de emisiones contaminantes $^{23}$. La Comisión concluyó que las decisiones sobre política energética debieran tener presente el cambio climático, considerando la promoción de energías renovables una medida necesaria para hacerle frente. Así, la política energética europea pasó a tratar los problemas ambientales de una forma global al reconocer que la energía es la mayor fuente de emisiones de GEI y admitir que ello podía llegar a ser el principal condicionante del uso de la energía ${ }^{24}$.

A mediados de los años 90 se adoptó un enfoque más equilibrado de la política energética europea, al tomar en consideración, junto a la competitividad y a la seguridad del suministro, la protección del medio ambiente. Precisamente, el Libro Verde sobre la energía presentado por la Comisión establecía esos tres ámbitos como los objetivos prioritarios de la política energética europea ${ }^{25}$. El texto reconocía que los temas energéticos y ambientales no podían examinarse ya de forma aislada. Según la Comisión, debía establecerse una estrategia energética europea a largo plazo con el fin de fomentar el uso de las energías renovables para la producción de electricidad dados sus beneficios ambientales, en particular en relación con el calentamiento global ${ }^{26}$.

Ya en 2006, un nuevo Libro Verde sobre la energía estableció los fundamentos de la citada nueva política energética europea, identificando los sectores en los que debía actuar la Unión ${ }^{27}$. La mitad de ellos tenían estrecha relación con el medio ambiente. Así, para lograr una combinación

${ }^{22}$ Masao Javier López Sako, «La política energética sostenible de la Unión Europea (1)», Noticias de la Unión Europea, n. ${ }^{\circ} 322$ (2011): 85.

${ }^{23}$ Comisión Europea, Comunicación de 3 de mayo de 1988, The main findings of the Commission's Review of Member State's energy policies, COM (88) 174 final.

${ }^{24}$ Comisión Europea, Comunicación de 8 de febrero de 1990, Energy and the environment, COM (89) 369 final.

${ }^{25}$ Comisión Europea, For a European Union Energy Policy - Green Paper, COM (94) 659 final/2 (1995).

${ }^{26}$ En desarrollo de esta nueva línea de actuación llegarían nuevas propuestas en torno a las energías renovables y a la dimensión energética del cambio climático: Comisión Europea, Energy for the Future: Renewable Sources of Energy - Green Paper, COM (96) 576 final (1996) y Comisión Europea, Comunicación de 14 de mayo de 1997, The Energy Dimension of Cimate Changue, COM (97) 196 final.

${ }^{27}$ Comisión Europea, Libro Verde: Estrategia europea para una energía sostenible, competitiva y segura, COM (2006) 105 final. 
energética más sostenible, eficiente y variada que favorezca la seguridad y la competitividad del suministro de energía, se apostó por fuentes de energía renovables. Al objeto de lograr un enfoque integrado de lucha contra el cambio climático, se impulsó la eficiencia energética y un uso más responsable, económico y racional de la energía. Finalmente, para fomentar la innovación en materia de energía, se apostó por reforzar y aumentar la investigación. La política energética quedaba así unida a la de medio ambiente, pues su gran objetivo, junto a la competitividad y la seguridad de abastecimiento, pasó a ser la sostenibilidad.

El Libro Verde, atendiendo a la preocupante situación de dependencia energética de la UE, situada entonces en el $66 \%$, pretendía «conformar un nuevo marco de actuación y unas nuevas tendencias en el sector energético» ${ }^{28}$. El texto señalaba como principales retos de la industria energética europea, además de que ésta compatibilizase su actividad con los objetivos medioambientales, la necesidad de hacer frente a la creciente dependencia de las importaciones de energía de la UE, teniendo en cuenta el crecimiento de la demanda a nivel mundial, la concentración de las principales reservas de combustibles fósiles en pocos países y los altos precios de la energía. La influencia del documento fue notoria en la legislación medioambiental europea, específicamente en lo que se refiere a las decisiones adoptadas para impulsar la lucha contra el cambio climático y el desarrollo de energías renovables ${ }^{29}$.

Con base en el citado Libro Verde, a principios de 2007 la UE presentó la estrategia para desarrollar una política energética con dos objetivos que la vinculan directamente con la política medioambiental ${ }^{30}$ : por un lado, el compromiso decidido a favor de una economía de bajo consumo, de energía más segura, más competitiva y más sostenible; por otro, la pretensión de que dicha política sirva para abordar la cuestión del cambio climático. La propuesta europea no era sino el resultado de la toma en consideración de las implicaciones ambientales en la producción y el consumo humanos de energía, de modo que ya no cabía concebir «una política energética que no tenga en cuenta como parte esencial de la misma su sostenibilidad, en pie de igualdad - como mínimo- con los aspectos de la seguridad del sumi-

28 Agustín Fernández de la Torre, «La realidad energética en la Unión Europea», Boletín Económico de ICE , n. ${ }^{\circ} 2887$ (2006): 15-16.

29 Desde entonces se ha ido desarrollando «un complejo normativo regulador del cambio climático y de las energías renovables» hasta el punto de que «ambas materias aparecen íntimamente imbricadas en la realidad diaria del sector energético y de las políticas públicas». José Francisco Alanza García y Miren Parasitar Iriarte, Cambio climático y energías renovables (Cizur Menor, Navarra: Thomson-Civitas, 2007), 13.

${ }^{30}$ Comisión Europea, Comunicación de 10 de enero de 2007, «Una política energética para Europa», COM (2007) 1 final. 
nistro y la competitividad» ${ }^{31}$. La estrategia es considerada particularmente relevante «por su contenido al incluir en la seguridad energética, los desafíos del cambio climático y la eficiencia energética ${ }^{32}$.

\section{El Tratado de Lisboa y la Estrategia Europa 2020}

El Tratado de Lisboa entró en vigor el 1 de diciembre de 2009. Desde entonces, los dos textos jurídicos fundamentales de la UE - el TUE y el Tratado de Funcionamiento de la Unión Europa (TFUE) - recogen los principios legales de la política de medio ambiente que orientan y limitan la actuación de las instituciones y que se regulan de manera más específica por medio de los programas de acción ambiental y por las disposiciones que los desarrollan ${ }^{33}$.

El TUE establece como objetivo de la UE el desarrollo sostenible, siendo la única región del mundo donde dicho objetivo es declarado principio constitucional ${ }^{34}$. Lo hace en su artículo 3 y en una doble perspectiva, tanto interior como exterior. En efecto, el número 3 de dicho precepto recoge, con respecto al mercado interior, que la Unión «obrará en pro del desarrollo sostenible de Europa», el cual se basará en tres elementos: un crecimiento económico equilibrado, una economía social de mercado y «un nivel elevado de protección y mejora de la calidad del medio ambiente». Mientras que el número 5 establece que «en sus relaciones con el resto del mundo, la Unión afirmará y promoverá sus valores», lo que supone contribuir, entre otras metas, al «desarrollo sostenible del planeta».

La política europea de medio ambiente se regula en el TFUE. Aún tratándose de una competencia compartida entre la Unión y sus Estados miembros (art. 4.2 TFUE), existe un elevado nivel de coordinación entre todos ellos, facilitado por la concreta normativa recogida en el Título XX (arts. 191 a 193). El primero de ellos establece los objetivos concretos de la política medioambiental de la UE: la conservación, la protección y la mejora de la calidad del medio ambiente; la protección de la salud de las personas; la utilización prudente y racional de los recursos naturales; el fomento de

31 López Sako, «La política energética...»,81.

${ }^{32}$ Rubén Herrero, «La seguridad energética y la estrategia global de seguridad de la Unión Europea», Revista UNISCI, n. ${ }^{\circ} 42$ (2016): 90.

${ }^{33}$ En este apartado, nos atenemos a las «Versiones consolidadas del Tratado de la Unión Europea y del Tratado de Funcionamiento de la Unión Europea»(DOUE, C 115 de 9 de mayo de 2008).

${ }^{34}$ Marthe Torre-Schaub, «L'apport du principe de développement durable au droit communautaire: gouvernance et citoyenneté écologique», Revue du Marché Commun et de l'Union Européenne, n. ${ }^{\circ} 555$ (2012): 89. 
medidas a escala internacional destinadas a hacer frente a los problemas regionales o mundiales del medio ambiente y en particular a luchar contra el cambio climático. La necesidad específica de luchar contra el cambio climático es una adición realizada por el Tratado de Lisboa, reflejo de la relevancia que para la UE había adquirido la cuestión.

La normativa fundamental europea reafirma el desarrollo sostenible como objetivo de la UE cuando recoge expresamente que «las exigencias de la protección del medio ambiente deberán integrarse en la definición y en la realización de las políticas y acciones de la Unión, en particular con objeto de fomentar el desarrollo sostenible» (art. 11 TFUE). Ello requiere, por un lado, que los objetivos y principios medioambientales deben ser perseguidos y aplicados en las demás políticas de la Unión del mismo modo que en la política de medio ambiente; y, por otro, que la normativa medioambiental debe entenderse e interpretarse de manera global, tomando en consideración todos los objetivos y principios en la legislación de esta materia ${ }^{35}$.

La integración ambiental en otras políticas es especialmente apreciable en la actualidad en lo que se refiere a la política energética europea. El Tratado de Lisboa introdujo la regulación independiente de esta materia en el Título XXI del TFUE, es decir, contigua a la normativa medioambiental. Su único precepto (art. 194) refleja el nexo entre ambas políticas pues establece en su número 1 los objetivos de la política energética «atendiendo a la necesidad de preservar y mejorar el medio ambiente». Dichos objetivos consisten en garantizar el funcionamiento del mercado de la energía; garantizar la seguridad de abastecimiento energético de la UE; fomentar la eficiencia energética y el ahorro energético así como el desarrollo de energías nuevas y renovables; y fomentar la interconexión de las redes energéticas. La existencia de una estrecha relación entre los ámbitos energético y medioambiental queda, así, evidenciado también en su vertiente normativa en el Derecho Originario de la UE ${ }^{36}$.

Ahora bien, a pesar del avance, el Tratado de Lisboa no logró eliminar la reticencia de los Estados miembros a ceder su soberanía energética ${ }^{37}$. En efecto, las medidas que adopte la UE, «no afectarán al derecho de un Estado miembro a determinar las condiciones de explotación de sus recursos energéticos, sus posibilidades de elegir entre distintas fuentes de energía y la es-

35 Kati Kulovesi, Elisa Morgera y Miquel Muñoz, «Environmental integration and multi-faceted International dimensions of EU law: unpacking the EU's 2009 climate and energy package», Common Market Law Review, n. 48 (2011): 834.

${ }^{36}$ Sobre esta cuestión, vid. Nicolas Moussis, EU Environment \& Energy Policies: Two Interwoven Legislative Areas (Rixensart, Bélgica: European Study Service, 2009).

37 Gemma Bedia Bueno, «El Derecho de la Energía, las Políticas Europeas y la Transición Energética en la Unión Europea», Cuadernos Cantabria Europa, n. ${ }^{\circ} 16$ (2017): 49. 
tructura general de su abastecimiento energético» (art. 194.2 TFUE). Por lo tanto, aunque se elaboren estrategias conjuntas en el seno de la UE, sobre el papel cada Estado «sigue siendo competente para adoptar sus propias decisiones en política de abastecimiento energético» ${ }^{38}$.

El Tratado de Lisboa también introdujo una novedad específica en el ámbito de la energía, vinculada a la preocupación existente en torno a la seguridad de abastecimiento. Se trata de la aplicación del principio de solidaridad recogido en el artículo 122 TFUE por el que, si un Estado miembro atraviesa graves dificultades de suministro energético, los demás le ayudarán a abastecerse.

Ya en 2010, la Comisión hacía pública su propuesta para preparar la economía de la UE de cara a la siguiente década: Europa 2020, aprobada por el Consejo Europeo en junio ${ }^{39}$. Esta estrategia se basa en tres áreas prioritarias interrelacionadas: crecimiento inteligente, desarrollando una economía basada en el conocimiento y la innovación; crecimiento sostenible, fomentando una economía de bajo nivel de carbono y eficiente en términos de recursos; y crecimiento integrador, estimulando una economía con un alto nivel de empleo.

Para progresar en dichas áreas la estrategia determinó cinco objetivos principales. En nuestro ámbito de estudio hay que subrayar el tercero de ellos, conocido como objetivo 20/20/20 en materia de clima y energía, derivado de las propuestas previas ya analizadas. Consiste en la reducción del $20 \%$ de las emisiones de GEI, o del $30 \%$ si se dan las condiciones para ello; el aumento del $20 \%$ de la proporción de energías renovables en el consumo total de energía; y la disminución del consumo de energía en un $20 \%$ logrando una mayor eficiencia energética. Con respecto a esta materia, la estrategia contiene una iniciativa fundamental denominada «Una Europa que utilice eficazmente los recursos». Por medio de la misma, se promueve el paso a una economía con pocas emisiones de carbono, desligando el crecimiento económico del uso de recursos y de energía, reduciendo las emisiones de $\mathrm{CO}_{2}$, reforzando la competitividad y promoviendo una mayor seguridad energética.

Tras la Estrategia Europa 2020, en noviembre de 2013, la UE aprobaba el Séptimo PMA para el periodo 2014-2020 ${ }^{40}$. Por medio del mismo, se

38 Morán Blanco, Seguridad..., 141.

39 Comisión Europea, Comunicación de la Comisión de 3 de marzo de 2010, Europa 2020. Una estrategia para un crecimiento inteligente, sostenible e integrador, COM (2010) 2020 final. En junio el Consejo Europeo aprobó la propuesta y la hizo suya. Consejo Europeo de Bruselas de 17 de junio de 2010 - Conclusiones, EUCO 13/10.

40 Decisión 1386/2013/UE del Parlamento Europeo y del Consejo, de 20 de noviembre de 2013, relativa al Programa General de Acción de la Unión en materia de Medio Ambiente hasta 2020 «Vivir bien, respetando los límites de nuestro planeta» (DOUE L 354/171 del 28 de diciembre de 2013). 
constató que ya no era posible seguir tratando al medio ambiente como algo ajeno a la economía, de modo que ésta debe ser transformada para obtener más valor con menos recursos y cambiar los modelos de consumo. Para ello, el programa «establece una estrategia medioambiental a largo plazo, lo suficientemente adaptable y flexible para dar respuesta a los múltiples retos (...) fijando el rumbo hacia una economía verde y competitiva que salvaguardará los recursos naturales y la salud de las generaciones presentes y futuras ${ }^{41}$. Como se ve, el programa trata de reforzar el impulso de actuaciones integradas en diferentes políticas y sectores, entre las que la energía es uno de los ámbitos principales ${ }^{42}$.

\section{La acción climática y su vinculación con la energía}

En diciembre de 2009, se desarrolló en Copenhague la $15 .{ }^{a}$ Conferencia de la Convención Marco de Naciones Unidas sobre Cambio Climático (COP 15), cuyo objetivo principal consistía en lograr un acuerdo mundial para suceder al Protocolo de Kioto, es decir, adoptar un texto jurídicamente vinculante sobre la reducción de las emisiones de GEI que debiera de entrar en vigor a partir del 1 de enero de $2013^{43}$. La Conferencia finalizó con la adopción de un acuerdo de mínimos no vinculante promovido conjuntamente por EEUU y los países del grupo BASIC (Brasil, Sudáfrica, India y China $)^{44}$. El acuerdo mantuvo como objetivo el límite de $2^{\circ} \mathrm{C}$ de subida del calentamiento global para 2050 , que podría rebajarse a $1,5^{\circ} \mathrm{C}$ en la posible

${ }^{41}$ Comisión Europea, Un medio ambiente sano y sostenible para las generaciones futuras, (Luxemburgo: OPOCE, 2013), 15.

${ }^{42}$ El Séptimo PMA partía de las diferentes iniciativas analizadas, «apostando claramente, y con tintes revolucionarios, por una economía baja en emisiones de carbono y con un modelo energético distinto, y con previsiones muy importantes en materia de recursos, energía, energías renovables, biodiversidad, eco-innovación, transportes, etc.». Dionisio Fernández de Gatta Sánchez, «El Séptimo Programa Ambiental de la Unión Europea, 2013-2020», Revista Aragonesa de Administración Pública, n. ${ }^{\circ} 41-42$ (2013): 93.

${ }^{43}$ Las Naciones Unidas asumían el objetivo de frenar en $2{ }^{\circ} \mathrm{C}$ la subida del calentamiento global, por medio de la reducción de las emisiones entre un $25 \%$ y un $40 \%$ para 2020 con respecto a los niveles de 1990 , llegando a una reducción de entre el $50 \%$ y el $80 \%$ para 2050. La UE acudió con su objetivo propio de reducción del $20 \%$ de sus emisiones, así como con su oferta de aumentar el compromiso de reducción al 30 \% siempre que los demás países desarrollados se comprometiesen a reducciones comparables y los países en desarrollo a una reducción acorde a sus capacidades.

${ }^{44}$ Naciones Unidas, «Decisión 2/CP.15 - Acuerdo de Copenhague», contenido en el Informe de la Conferencia de las Partes sobre su $15^{\circ}$ período de sesiones, celebrado en Copenhague del 7 al 19 de diciembre de 2009 - Segunda parte: Medidas adoptadas por la Conferencia de las Partes en su $15^{\circ}$ período de sesiones (FCCC/CP/2009/11/Add.1), de 30 de marzo de 2010, 4-11. 
revisión del acuerdo en 2015. Aunque se admitió la necesidad de reducir en profundidad las emisiones de GEI, no estableció un límite concreto de emisiones a los países.

Ante el fracaso que supuso la reunión de Copenhague, la Comisión, a la par que presentaba la Estrategia Europa 2020, hacía pública una estrategia específica para contribuir a mantener el impulso de los esfuerzos internacionales en la lucha contra el cambio climático ${ }^{45}$. Ante la falta de consenso en el modo de luchar contra el cambio climático, la UE trató de reforzar su liderazgo en la materia adoptando un nuevo punto de vista: vincular la batalla contra el calentamiento global con la seguridad energética, materia que los países atienden en términos exclusivamente nacionales ${ }^{46}$. Precisamente, la dependencia externa de la UE ha supuesto que haya «centrado su política energética en el objetivo prioritario de garantizar la seguridad energética», y para el logro de la misma «la eficiencia energética, el desarrollo de energías alternativas y la innovación tecnológica destacan como apuestas estratégicas esenciales» ${ }^{47}$.

Lo cierto es que la producción normativa de la UE ya estaba reflejando la estrecha relación entre la lucha contra el cambio climático y la energía, principalmente por medio del impulso a las energías renovables. En efecto, en enero de 2008 la Comisión había publicado un paquete global de medidas sobre la protección del clima y la energía, cuyo resultado fueron relevantes actos legislativos ${ }^{48}$. Precisamente, la apuesta por fortalecer y desarrollar las energías renovables no sólo tenía ya por objetivo mejorar la seguridad y fiabilidad del abastecimiento, sino que además quedaba claro, «más que nunca, que el desarrollo de los recursos energéticos renovables en Europa es un factor fundamental en la batalla contra el cambio

45 Comisión Europea, Comunicación de 9 de marzo de 2010, La política climática internacional posterior a Copenhague: una intervención inmediata para reactivar la lucha global contra el cambio climático, COM (2010) 86 final.

46 Pau Isbell y Federico Steinberg, «Key Strategic Decisions for Europe in Energy and Climate Change, Análisis del Real Instituto Elcano (ARI), 2010 , n. ${ }^{\circ} 76$ (2010): 3.

${ }^{47}$ Beatriz Pérez de las Heras, «Las políticas de seguridad energética en la Unión Europea y los Estados Unidos: desafíos globales y compromisos comunes en la transición hacia un modelo energético más sostenible», Revista de Derecho Comunitario Europeo, n. ${ }^{\circ} 47$ (2014): 15.

${ }^{48}$ El conocido como «Paquete energía y clima» estaba compuesto por los siguientes actos legislativos aprobados por el Parlamento Europeo y el Consejo el 23 de abril de 2009 (todos en DOCE L 140, de 5 de junio de 2009): Directiva 2009/28/CE, relativa al fomento del uso de energía procedente de fuentes renovables; Directiva 2009/29/CE, por la que se perfecciona el comercio de derechos de emisión de gases de efecto invernadero; Directiva 2009/31/ CE, sobre el almacenamiento geológico del dióxido de carbono; Decisión 406/2009/CE sobre el esfuerzo de los Estados miembros para reducir sus emisiones de gases de efecto invernadero a fin de cumplir los compromisos adquiridos por la Comunidad hasta 2020. 
climático» ${ }^{49}$. Aún más, desde entonces, «las energías renovables constituyen una pieza fundamental de las políticas energéticas más recientes aprobadas en el nivel Europeo, posibilitando una orientación ambiental de las mismas, en el marco más amplio de una estrategia internacional de lucha contra el cambio climático ${ }^{50}$.

Siguiendo esa idea, la UE presentó una propuesta para una energía competitiva, sostenible y segura ${ }^{51}$. A partir de los objetivos energéticos de la Unión ya fijados $(20 / 20 / 20)$, se establecieron las prioridades energéticas concretas. Entre las mismas, destacaban las siguientes: el ahorro del $20 \%$ de energía hasta 2020; el desarrollo de nuevas tecnologías innovadoras de alto rendimiento y baja intensidad de carbono; y el refuerzo de acuerdos internacionales que promuevan un futuro energético con bajas emisiones de carbono a nivel mundial. Siguiendo dicha vía, la Comisión dio a conocer a finales de 2011 los caminos posibles para conseguir la eliminación del carbono del sistema energético de la UE ${ }^{52}$ : ahorro energético, aumento del porcentaje de las energías renovables en el suministro energético, construcción de infraestructuras que favorezcan la penetración de las energías renovables, integración de los mercados de la energía en Europa, inversión en tecnologías con bajas emisiones de carbono.

Resultado de esta estrategia fue la concreción en la COP 18 celebrada en diciembre de 2012 en Doha (Qatar) de un segundo periodo de vigencia del Protocolo de Kioto. La UE consiguió poner de su lado a China, para entonces el mayor contaminante del planeta, que si bien no estaba obligada por el Protocolo al ser considerado aún país en desarrollo, presentó relevantes objetivos de reducción de emisiones y arrastró en dicho camino a otras economías emergentes contaminantes como Brasil. El conocido como Kioto II, entraba en vigor en enero de 2013 y estará vigente hasta el 31 de enero de $2020^{53}$. No obstante, tras la retirada del Protocolo de Japón, Ca-

49 Comisión Europea, Comunicación de 24 de abril de 2009, Informe de avance sobre la energía procedente de fuentes renovables, COM (2009) 192 final, 11.

50 Manuela Mora Ruiz, «La ordenación jurídico-administrativa de las energías renovables como pieza clave en la lucha contra el cambio climático: ¿Un sector en crisis?», Actualidad Jurídica Ambiental, n. ${ }^{\circ} 32$ (2014): 39.

${ }^{51}$ Comisión Europea, Comunicación de 10 de noviembre de 2010, Energía 2020: Estrategia para una energía competitiva, sostenible y segura, COM (2010) 639 final.

52 Comisión Europea, Comunicación de 15 de diciembre de 2011, Hoja de Ruta de la Energía para 2050, COM (2011) 885 final.

53 Naciones Unidas, «Decisión 1/CMP.18 - Enmienda al Protocolo de Kioto de conformidad con su artículo3, párrafo 9 (Enmienda de Doha)», contenido en el Informe de la Conferencia de las Partes en el Protocolo de Kioto sobre su octavo período de sesiones, celebrado en Doha del 26 de noviembre al 8 de diciembre de 2012 - Segunda parte: Medidas adoptadas por la Conferencia de las Partes en el Protocolo de Kioto sobre su octavo período de sesiones (FCCC/KP/CMP/2012/13/Add.1), de 28 de febrero de 2013, 2-14. 
nadá y Nueva Zelanda, únicamente quedaban obligados durante el periodo de prórroga la UE, Australia, Noruega, Islandia, Croacia, Kazajistán, Liechtenstein y Mónaco, países que en conjunto sólo suponen el $15 \%$ de las emisiones mundiales ${ }^{54}$.

Aunque seguía sin cumplirse el objetivo principal - la consecución de un texto vinculante que sustituya al Protocolo de Kioto-, hay que reconocer el relevante papel que la UE mantenía en la batalla contra el cambio climático $^{55}$. Los tres principales argumentos que le habían otorgado dicha posición podían reforzar su posición y llevarle al liderazgo en la escena internacional: en primer lugar, el hecho de que la política climática, como elemento fundamental para el desarrollo sostenible, se hubiese convertido en objetivo del proceso de integración europea en general; en segundo lugar, la postura de la Unión de vincular la seguridad energética con el desarrollo sostenible, lo que había reforzado la relevancia de la agenda climática; en tercer lugar, la importancia otorgada por la Unión al multilateralismo como requisito para lograr resultados eficaces en la lucha contra el cambio climático ${ }^{56}$.

\section{Los instrumentos más recientes de la UE para hacer frente a los retos de la seguridad energética y el cambio climático}

\section{El Marco clima y energía para 2030}

En enero de 2014 la Comisión presentó los logros parciales del objetivo 20/20/20 en el seno de una propuesta para un nuevo marco para las políticas de clima y energía de cara a $2030^{57}$. La Comisión entendía que el avance en el cumplimiento del objetivo establecido en la Estrategia Europa 2020 podía verse reforzado mediante la determinación de objetivos específicos para 2030 en este ámbito. Como se verá a continuación, la UE apostaba definiti-

${ }^{54}$ Según el Anexo B del Protocolo de Kioto, tras la Enmienda de Doha, el objetivo de reducción de emisiones para 2020 por parte de los firmantes, con respecto de los niveles de 1990, son los siguientes: Ucrania, 24 \%; Mónaco, 22 \%; UE e Islandia, 20 \%; Noruega y Liechtenstein, $16 \%$; Suiza, 15,8 \%; Bielorrusia, $12 \%$; Kazajstán, $5 \%$; Australia (cuyo año de referencia es 2000), 0,5\%.

55 Para un análisis sobre esta cuestión, vid. Justo Corti Varela, «Contribuciones de la Unión Europea a los desafíos que representa la protección del medio ambiente: La diplomacia europea en materia de lucha contra el cambio climático», Cuadernos Europeos de Deusto, n. 57 (2017).

56 Alexander S. Gusev, «Climate Change Issues in a Transatlantic Context», L'Europe en formation, n. 369 (2011): 80-85.

57 Comisión Europea, Comunicación de 22 de enero de 2014, Un marco estratégico en materia de clima y energía para el período 2020-2030, COM (2014) 15 final. 
vamente por el recurso a la política energética como herramienta eficaz en la lucha contra el cambio climático, contribuyendo así a la defensa del medio ambiente.

Lo cierto es que el cumplimiento del objetivo 20/20/20 estaba bien encaminado: con respecto a 1990, en 2012 las emisiones de GEI se redujeron el $18 \%$ y se preveía que la reducción llegase al $24 \%$ en 2020 y al $32 \%$ en 2030; la cuota de las energías renovables se incrementó al $13 \%$ en 2012, en proporción al consumo final de energía, y se preveía que aumentase hasta el $21 \%$ en 2020 y el $34 \%$ en 2030; la UE había instalado aproximadamente el $44 \%$ de la electricidad procedente de fuentes renovables (exceptuando la energía hidroeléctrica) a finales de 2012; la intensidad energética de la economía de la UE disminuyó un $24 \%$ entre 1995 y 2011, mientras que la intensidad de carbono se redujo un $28 \%$. La Comisión también puso de relieve, poco después, que ante la constatación de la posibilidad de lograr un ahorro energético para 2020 del $20 \%$, procedía «mantener la dinámica actual de ahorro de energía y proponer un objetivo ambicioso en materia de eficiencia energética del $30 \% »^{58}$.

El Consejo Europeo aprobó el «Marco de actuación en materia de clima y energía hasta el año 2030» en octubre de $2014^{59}$, en el que adoptó como propios de la UE los objetivos propuestos por la Comisión. En primer lugar, se fijó como objetivo vinculante para la UE, la reducción de las emisiones de GEI por lo menos en un $40 \%$ para 2030 con respecto a los valores de $1990^{60}$. En segundo lugar, también como objetivo vinculante, se estableció que la cuota de energías renovables dentro del consumo energético total de la UE en 2030 sea como mínimo del $27 \%$. En tercer lugar, se fijó a escala de la UE un objetivo indicativo de mejora de la eficiencia energética al menos en un $27 \%$ en 2030 , que se revisará antes de 2020 para su posi-

58 Comisión Europea, Comunicación de 23 de julio de 2014, La eficiencia energética y su contribución a la seguridad de la energía y al marco 2030 para las políticas en materia de clima y energía, COM (2014) 520 final, 17.

59 Consejo Europeo de Bruselas de 23 y 24 de octubre de 2014 - Conclusiones de la Presidencia, EUCO 169/14.

${ }^{60}$ Dado que la implementación de Kioto II «supone la proyección internacional de los objetivos diseñados en la normativa interna» de la UE (Estrategia Europa 2020) y que el paquete sobre clima y energía «supone un amplio entramado en el que tanto la política de cambio climático como la energética confluyen para alcanzar los objetivos previstos de reducción de emisiones», es posible concluir que «las previsiones del segundo periodo de cumplimiento del Protocolo de Kioto y del paquete sobre clima y energía quedan interrelacionadas, y suponen el escenario de influencia internacional y el compromiso interno de la Unión Europea en materia de cambio climático». Rosa Giles Carnero, «La contribución de la Unión Europea al desarrollo del régimen internacional en materia de cambio climático: el paquete europeo sobre clima y energía en el contexto de la acción internacional», Cuadernos Europeos de Deusto, . $^{\circ} 57$ (2017): 203. 
ble aumento al $30 \%{ }^{61}$. Además, el Consejo Europeo calificó de capital importancia la realización de un mercado interior de la energía que funcione plenamente y esté completamente conectado, por lo que se estableció como objetivo para 2030 un interconexión eléctrica del $15 \%$ entre los países de la $\mathrm{UE}^{62}$.

Este nuevo objetivo 40/27/27 para 2030 fue considerado ambicioso desde la propia UE, si bien el Parlamento Europeo se había mostrado a favor de aumentar dichos objetivos ${ }^{63}$. No obstante, visto el grado de cumplimiento del objetivo 20/20/20 para 2020 al que nos hemos referido arriba, no parece que se tratase de fines particularmente exigentes ni que requiriesen de esfuerzos adicionales con dificultad excesiva. Ello se debe a que los objetivos establecidos son fruto del «equilibrio político (...) entre las posiciones más proambientalistas y las que reflejan una mayor preocupación por el impacto en la competitividad de la economía» ${ }^{64}$. Por otro lado, se ha criticado la excesiva capacidad de influencia que pudieron haber tenido las asociaciones industriales y las empresas del sector eléctrico, especialmente durante el período de consulta y reflexión que dio lugar al Marco energía y clima para 2030, en el sentido de que la Comisión siguió en su propuesta muchas de las peticiones que las grandes empresas de la energía venían realizando en los últimos tiempos ${ }^{65}$.

${ }^{61}$ Tanto para el segundo como para el tercer objetivo, los Estados miembros podrán fijar sus propios objetivos nacionales más elevados que los generales para el conjunto de la UE.

62 La Comisión había propuesto en 2012 la consecución del mercado interior de la energía para 2014, algo que no iba a tener lugar visto el retraso de numerosos Estados miembros en la transposición y aplicación integral de la normativa europea correspondiente. Comisión Europea, Comunicación de 3 de octubre de 2012, Acta del Mercado Único II - Juntos por un nuevo crecimiento, COM (2012) 573 final. A pesar del objetivo establecido, resultaba evidente una vez más «que los Estados se resisten a perder su soberanía energética, por lo que los objetivos de garantizar el funcionamiento del mercado de la energía y fomentar la interconexión de las redes energéticas resultan más formales y teóricos que prácticos y reales». Pérez de las Heras, «Las políticas...», 23.

${ }^{63}$ En efecto, aunque el PE compartía el objetivo vinculante de reducción de las emisiones de GEI en un $40 \%$ para 2030 con respecto a 1990, pedía aumentar el objetivo de eficiencia energética también al $40 \%$ para 2030, así como que la cuota de energías renovables dentro del consumo energético total de la UE en 2030 sea del $30 \%$. Parlamento Europeo, Resolución de 5 de febrero de 2014, sobre un marco para las políticas de clima y energía en 2030 (2013/2135(INI), DOUE C 93, de 24 de marzo de 2017, 87.

${ }^{64}$ Claudio Aranzadi, «UE 2030: objetivo clima y energía», Política Exterior, vol. 29, n. ${ }^{\circ} 163$ (2015): 46.

65 Siguiendo esa argumentación, se afirma que «se ha impuesto la idea de la necesidad de sacrificar los objetivos climáticos con el fin de impulsar la competitividad industrial». Ana Moreno Regaña, «Hegemonía y capital transnacional en la Unión Europea. El marco para el clima y la energía», Relaciones Internacionales, n. ${ }^{\circ} 31$ (2016): 107. 


\section{La estrategia de seguridad energética}

Como sucede en la mayoría de los países importadores netos de energía, la seguridad energética en la UE se asociaba a la seguridad de suministro, cada vez más dependiente de las importaciones ${ }^{66}$. Por ello, tras las alteraciones temporales sufridas en el abastecimiento de gas durante los inviernos de 2006 y 2009, la inestabilidad derivada de la Primavera Árabe de 2011 y ante la situación que se estaba viviendo en Ucrania, la UE debía comenzar a disminuir su vulnerabilidad a las perturbaciones energéticas externas. Tras una primera propuesta de $2011^{67}$, en la que destaca el objetivo de reforzar la cooperación con terceros países proveedores de energía, la Comisión hizo pública en mayo de 2014 la Estrategia Europea de la Seguridad Energética ${ }^{68}$, con el fin de avanzar en diversas áreas para contrarrestar la vulnerabilidad de abastecimiento.

Según los datos manejados por la Comisión, los Estados miembros de la UE son en su mayoría grandes consumidores de combustibles fósiles y, salvo alguna excepción, son vulnerables energéticamente hablando. En efecto, la UE importa el $53 \%$ de la energía que consume. La dependencia de las importaciones afecta al crudo (casi el $90 \%$ ), al gas natural $(66 \%)$ y, en menor medida, a los combustibles sólidos (42\%) y al combustible nuclear $(40 \%)$. La cuestión de la seguridad del abastecimiento de energía afecta a todos los Estados miembros, aunque algunos sean más vulnerables que otros, en particular las regiones menos integradas y conectadas, como el Báltico y Europa Oriental ${ }^{69}$. No deben dejarse de lado otros problemas adicionales, como «la vejez de las infraestructuras, que no pueden absorber

66 «En la primera década de 2000 la dependencia energética medida como las importaciones netas de energía para el conjunto de los 27 miembros aumentaba desde un 75,7 \% (2000) a un 84,3\% (2010) para el petróleo, y de un 48,9\% (2000) a un 62,4 \% (2010) para el gas y la tendencia continúa al alza». Javier Valdés, «Evolución y consistencia en la política de seguridad energética de la UE: los Proyectos de Interés Común», Papeles de Europa, vol. 29, n. ${ }^{\circ} 2$ (2016): 70.

67 Comisión Europea, Comunicación de 7 de septiembre de 2011, Sobre la seguridad de abastecimiento energético y la cooperación internacional «La política energética de la UE: establecer asociaciones más allá de nuestras fronteras», COM (2011) 539 final.

${ }^{68}$ Comisión Europea, Comunicación de 28 de mayo de 2014, Estrategia Europea de la Seguridad Energética, COM (2014) 330 final.

${ }^{69}$ Como subraya la Comisión en su comunicación, «el problema más acuciante de la seguridad del abastecimiento de energía es la fuerte dependencia de un único suministrador externo, especialmente en el caso del gas», puesto que «seis Estados miembros dependen de Rusia como único suministrador externo para la totalidad de sus importaciones de gas y tres de ellos utilizan gas natural para más de una cuarta parte de sus necesidades energéticas totales». Comisión, Estrategia..., 2. Sobre esta cuestión, vid. Morán Blanco, Seguridad..., 97-131 (Capítulo 3: «La dependencia energética de la Unión Europea»). 
la producción creciente de las renovables; la existencia de 28 marcos regulatorios nacionales; la existencia de (...) países que no tienen suficientes conexiones con sus vecinos; y que los clientes domésticos no tienen suficientes alternativas de suministro» ${ }^{70}$.

La estrategia nace vinculada al Marco clima y energía para 2030, del que forma parte, pues «la seguridad energética de la Unión es inseparable de la necesidad de avanzar hacia una economía competitiva de bajo carbono que reduzca el uso de combustibles fósiles importados». Para lograrlo, por un lado, la estrategia pretende mantener e impulsar la tendencia ya existente, referida al hecho de que «la UE es el único gran actor económico que produce el $50 \%$ de su electricidad sin emisiones de gases de efecto invernadero» ${ }^{71}$. Por otro lado, la estrategia establece los pilares en que debe basarse la cooperación entre los Estados miembros para adoptar medidas que respondan a las cuestiones de seguridad energética: aumentar la capacidad de la UE para hacer frente a problemas energéticos graves; reforzar los mecanismos de emergencia y solidaridad; moderar la demanda de energía; desarrollar un mercado interior efectivo e integrado; aumentar la producción de energía en la UE; reforzar el desarrollo de las tecnologías energéticas; diversificar las fuentes externas de abastecimiento; mejorar la coordinación de las políticas energéticas nacionales y actuar con una sola voz en la política energética exterior.

Posteriormente, la seguridad energética va a quedar englobada entre las prioridades de la Estrategia global para la política exterior y de seguridad de la UE ${ }^{72}$. Dicha estrategia determina que los desafíos a los que se enfrenta la seguridad de la UE son «el terrorismo, las amenazas híbridas, la volatilidad económica, el cambio climático y la inseguridad energética» ${ }^{73}$. Entre las líneas de acción que la UE debe desarrollar para garantizar la seguridad se establece, precisamente, la seguridad energética. A este respecto, en la dimensión exterior y «en consonancia con los objetivos de la Unión

${ }^{70}$ Francisco J. Ruiz González, «El reto de la seguridad energética para la Unión Europea», Revista de Derecho, Empresa y Sociedad, n. ${ }^{\circ} 6$ (2015): 119.

${ }^{71}$ Debe subrayarse que la propia Comisión especifica que dicho porcentaje surge de la suma del $23 \%$ de energías renovables y el $27 \%$ de energía nuclear. Comisión, Estrategia..., 3 .

72 «Una visión común, una actuación conjunta: una Europa más fuerte», Documento de la Alta Representante de la Unión para Asuntos Exteriores y Política de Seguridad, acceso el 30 de octubre de 2018, https://europa.eu/globalstrategy.

73 Aunque resulta positivo que también el cambio climático sea especificado como desafío para la seguridad, lo cierto es que la estrategia incide en dicho fenómeno más como uno de «los factores que agravan o potencian los riesgos y amenazas existentes» y «no se hace mención al problema medioambiental o climático en la parte del documento dedicada a la seguridad energética». Carlos Del Río, «El cambio climático en la estrategia global de seguridad de la Unión Europea», Revista UNISCI, n. ${ }^{\circ} 42$ (2016): 74. 
de la Energía, la UE tratará de diversificar sus fuentes, proveedores y rutas de energía, especialmente en el ámbito del gas, y de promover el máximo nivel de seguridad nuclear en terceros países»; mientras que en el plano interior «la UE trabajará en la creación de un mercado interior de la energía plenamente operativo, se centrará en la energía sostenible y la eficiencia energética» ${ }^{74}$. A este respecto, la insuficiente capacidad de interconexión sigue siendo un obstáculo para lograr un mercado energético europeo bien conectado, lo que precisamente «es una precondición para crear la Unión de la Energía y constituye un factor fundamental para reforzar en toda Europa la seguridad de suministro energético» ${ }^{75}$.

\section{La Unión de la Energía}

Vistas las herramientas analizadas, la Comisión consideró que la UE contaba ya «con las competencias y los instrumentos necesarios para poner en práctica una política energética cuyos objetivos sean: asegurar el abastecimiento energético, garantizar que los precios de la energía no sean un freno para la competitividad, proteger el medio ambiente y luchar contra el cambio climático, y mejorar las redes energéticas ${ }^{76}$. En desarrollo de dicha idea, la UE lanzó en 2015 la estrategia para la Unión de la Energía, a partir de la propuesta presentada por la Comisión en febrero ${ }^{77}$. El objetivo de la misma, «centrada en una política climática ambiciosa, es ofrecer (...) una energía segura, sostenible, competitiva y asequible», para lo que se desarrollan acciones en cinco dimensiones estrechamente relacionadas: seguridad energética, un mercado europeo de la energía plenamente integrado, la eficiencia energética, la descarbonización de la economía, y la investigación y la innovación en el ámbito energético.

La interrelación de las dimensiones se aprecia claramente en lo referido a la seguridad energética, pues como factores clave de la misma se citan «la realización del mercado interior de la energía y un consumo de energía más eficiente». Del mismo modo, la necesaria diversificación de fuentes de energía, proveedores y rutas, además de ser crucial para garantizar un sumi-

74 «Una visión común...», 14.

75 José Luis De Castro Ruano, «La Unión Europea avanza hacia la unión de la energía», Unión Europea Aranzadi, n. ${ }^{\circ} 4$ (2015): 21.

${ }^{76}$ Comisión Europea, Comprender las políticas de la Unión Europea: Energía, (Luxemburgo: OPOUE, 2014), 4.

77 Comisión Europea, Comunicación de 25 de febrero de 2015, Estrategia Marco para una Unión de la Energía resiliente con una política climática prospectiva, $\mathrm{COM(2015)} 80$ final. El Consejo Europeo adoptó el compromiso correspondiente en marzo. Consejo Europeo de Bruselas de 19 y 20 de marzo de 2015 - Conclusiones de la Presidencia, EUCO 11/15. 
nistro energético seguro y unos precios asequibles y competitivos, impulsa a apostar por las energías renovables, necesarias para la descarbonización de la economía. En esta dimensión se refuerza la importancia, a nivel interno, de colaborar entre los Estados miembros en materia de seguridad de suministro y, en el plano externo, de reforzar el papel de Europa en los mercados mundiales de la energía ${ }^{78}$. La relevancia de esta dimensión se fortaleció poco después al quedar integrada la Estrategia Europea de la Seguridad Energética en la Unión de la Energía, al ser considerada una prioridad permanente, no sólo en periodos de crisis ${ }^{79}$.

La consecución de un mercado integrado de la energía en la UE tiene por objeto desarrollar un sistema energético europeo más eficaz. Para ello se apuesta por la interconexión entre los Estados miembros y el intercambio de energía entre los mismos. Se fomentará, asimismo, la cooperación regional en materia energética, siempre en el marco común de la UE. Se trata de una dimensión relevante para la integración del mercado interior de la energía, no en vano hasta la fecha la aplicación de mecanismos propios por parte de los Estados miembros ha causado conflictos entre las instituciones de la UE y las nacionales. Por ello, frente a la defensa de los intereses de cada Estado se requiere la solidaridad entre países y regiones, pues «solo el correcto encaje entre los intereses europeos, nacionales y regionales, pueden permitir la creación de una verdadera Unión Europea de la energía» ${ }^{80}$.

La dimensión referida a la eficiencia energética se plantea como contribución a la moderación de la demanda de energía. A este respecto, el Marco clima y energía para 2030 quedaba también integrado en la estrategia para la Unión de la Energía, al asumirse plenamente el mencionado objetivo 40/27/27, así como la posible ampliación del objetivo de eficiencia energética al $30 \%$ antes de $2020^{81}$. Se subraya la importancia de incrementar la

78 Aunque la Comisión no lo menciona, la UE también deberá «abordar las consecuencias energéticas del Brexit, que implica perder un socio energético de perfil alto que contribuye de manera importante a la proyección energética europea a nivel global». Herrero, «La seguridad energética...», 92 .

79 Así se recoge en el documento de trabajo adjunto al Primer informe sobre el estado de la Unión de la Energía, COM (2015) 572 final. Comisión Europea, State of the Energy Union 2015. Commission Staff Working Document on the European Energy Security Strategy, SWD (2015) 404 final, 10.

${ }^{80}$ Javier De Carlos Izquierdo, «La estrategia de seguridad energética de la Unión Europea y España», Boletín I.E.E.E., n. ${ }^{\circ} 1$ (2016): 561.

${ }^{81}$ Lo cierto es que la Unión de la Energía no sólo toma en consideración los objetivos previstos para 2030, sino también la hoja de ruta 2050. «Es en el marco de estos objetivos que ha de entenderse la unión energética». Natalia Fabra Portela, «La Unión Energética: instrumento para la transición energética en Europa», Información Comercial Española ICE, n. ${ }^{\circ} 902$ (2018): 66. 
eficiencia energética en dos sectores específicos como son la construcción y el transporte, lo que de nuevo nos pone de relieve la interrelación de las dimensiones, pues el objetivo citado supone impulsar al mismo tiempo la descarbonización, especialmente del transporte, apostando por las energías renovables y el desarrollo de combustibles alternativos.

La descarbonización de la economía está íntimamente ligada con la acción climática, principalmente por medio de la reducción de emisiones de GEI y la apuesta por las energías renovables. De nuevo, la conexión con el Marco energía y clima para 2030 y el objetivo 40/27/27, a lo que se añade el hecho de que la mira estaba puesta en la próxima COP - la 21, a celebrar en París - , al objeto de lograr un acuerdo global jurídicamente vinculante para la reducción de emisiones.

Finalmente, la dimensión relativa a la investigación, la innovación y la competitividad en el ámbito de la energía redunda en la interrelación de todas las dimensiones previstas en la Unión de la Energía. Así, se menciona la necesidad de desarrollar una nueva generación de tecnologías renovables y soluciones de almacenamiento, lo que favorecerá tanto la seguridad como la eficiencia energéticas y, al mismo tiempo, la reducción de emisiones de GEI. Resulta nuevamente llamativo que se siga apostando por la energía nuclear, pues la estrategia expone que «la UE debe procurar mantener el liderazgo tecnológico en el ámbito nuclear (...) de forma que no aumente su dependencia energética», aunque al menos se exige garantizar «que los Estados miembros apliquen las normas más estrictas en materia de seguridad, protección, gestión de residuos y no proliferación» ${ }^{82}$.

Como se ve, la Unión de la Energía es la respuesta común que la UE planteó para producir una transición energética ante los diversos acontecimientos que estaban teniendo lugar en el mundo y que complicaban los objetivos europeos en materia de seguridad energética, lucha contra el cambio climático y protección del medio ambiente: la guerra de Ucrania, la desconfianza con respecto a Rusia, los bajos precios del carbón, la crisis económica, el incremento de la dependencia de importaciones energéticas, el auge de recursos no convencionales ${ }^{83}$. Precisamente, con respecto de estos últimos y en comparación con el éxito que ha tenido la explotación de los hidrocarburos no convencionales en EEUU, «para Europa no cabe pensar en escenarios de producción similares en el corto plazo ni es una opción relevante desde el punto de vista del abaratamiento general de los costes energéticos» ${ }^{84}$.

82 Comisión Europea, Estrategia Marco..., 18-19.

83 Herrero, «La seguridad energética...», 91.

84 Teresa Ribera et al. «La Unión Europea y la revolución americana de los no convencionales», Economía Exterior, n. ${ }^{\circ} 68$ (2014): 37. 
No obstante, resulta llamativo, al margen de que desde la UE se siga apostando por la energía nuclear para la descarbonización (por cuanto energía no emisora de GEI), que la Comisión incluya como opción para reducir la dependencia energética de Europa la producción de petróleo y gas de fuentes no convencionales. Al menos, se agradece que sólo se vea como «una alternativa posible, siempre que se tengan debidamente en cuenta los problemas de aceptación pública y de impacto ambiental» ${ }^{85}$. Es evidente que la apuesta más segura para la UE, tanto económica como energética, sigue siendo un proceso colectivo de transición que posibilite un sistema más eficiente y una mayor proporción de energías renovables, y parece que la Unión de la Energía se encamina hacia ese fin. No obstante, debe tenerse presente que «las soluciones tecnológicas de baja intensidad en carbono a costes razonables son determinantes en la aminoración de riesgos colectivos y en la construcción de alternativas a estrategias de explotación de hidrocarburos no convencionales» ${ }^{86}$.

Hasta la fecha, la Comisión ha emitido tres informes sobre el estado de la Unión de la Energía ${ }^{87}$. En el tercero de ellos, de finales de 2017, se determinó que la Unión de la Energía debe ser una realidad para 2019 vistos los avances habidos en el conjunto de la UE. Entre los mismos se citaban la cuota lograda en 2015 del 16,7 \% de consumo de energía proveniente de fuentes renovables, la reducción de emisiones de GEI por debajo del $80 \%$ en 2016 con respecto a los niveles de 1990, o la disminución constante de la demanda de la energía (la UE consumió un 2,5\% menos de energía primaria que en 1990, cuando en dicho período el PIB había crecido el $53 \%$ ). Por el contrario, se insiste en la necesidad de seguir reduciendo el consumo de energía y aumentar la eficiencia, así como evitar los obstáculos en la transición a la energía limpia, como la competencia desleal que puede generar el mantenimiento por parte de los Estados miembros de subsidios a los combustibles fósiles ${ }^{88}$.

${ }^{85}$ Comisión Europea, Estrategia Marco..., 5-6.

${ }^{86}$ Ribera, «La Unión Europea...», 39.

87 Comisión Europea, Comunicación de 18 de noviembre de 2015, Estado de la Unión de la Energía 2015, COM (2015) 572 final; Comunicación de 1 de febrero de 2017, Second Report on the State of the Energy Union, COM (2017) 53 final; Comunicación de 23 de noviembre de 2017, Third Report on the State of the Energy Union, COM (2017) 688 final.

${ }^{88}$ La necesidad de realizar mayores esfuerzos es más evidente en unos Estados miembros que en otros, pues el avance en el cumplimiento de los objetivos energéticos es desigual entre ellos. «El riesgo es consolidar una Europa a dos velocidades que ponga en peligro la Unión de la Energía». Tomás Gutiérrez Roa, «La Unión de la Energía y su impacto en las relaciones exteriores comunitarias», Boletín I.E.E., n. ${ }^{\circ} 10$ (2018): 922. 


\section{El Acuerdo de París}

Tanto el Marco clima y energía para 2030 como la estrategia para la Unión de la Energía marcaron las bases de la postura que la UE llevaría a la COP 21, a celebrar en París en 2015. En las dos conferencias previas preparatorias de la de París, la UE trató de mostrar una apuesta fortalecida por una acción eficaz en la lucha contra el cambio climático ${ }^{89}$. Ello supuso un relevante cambio en sus compromisos de reducción de emisiones de GEI, doblando el porcentaje propuesto. En efecto, la Unión se comprometió a reducir sus emisiones en al menos el $40 \%$ para 2030 en comparación con los niveles de 1990, y llegar a un nivel de reducción de entre el 80 y el $95 \%$ para 2050, para liderar de este modo una reducción global mundial del $50 \%$.

La COP 21 se celebró en París entre el 30 de noviembre y el 11 de diciembre de 2015. Los 195 países participantes adoptaron por consenso el conocido como «Acuerdo de París»" lante y universal. Entre sus contenidos, destaca el compromiso para reducir las emisiones de GEI con el fin de mantener el aumento de la temperatura media anual por debajo de $2{ }^{\circ} \mathrm{C}$ con respecto a los niveles preindustriales, e incluso a realizar esfuerzos para limitar dicho aumento a $1,5^{\circ} \mathrm{C}$. Todos los firmantes del acuerdo deben presentar planes de mitigación de sus emisiones (a diferencia del Protocolo de Kioto, en el que sólo los países desarrollados estaban obligados a reducir sus emisiones), si bien cada país fija la meta de reducción de emisiones que considere oportuna para lograr el objetivo global de mantenimiento del aumento de la temperatura. Por lo tanto,

${ }^{89}$ Consejo de la Unión Europea, Preparativos del $20 .^{\circ}$ periodo de sesiones de la Conferencia de las Partes de la Convención Marco de las Naciones Unidas sobre Cambio Climático y del 10. ${ }^{\circ}$ periodo de sesiones de la Reunión de las Partes en el Protocolo de Kioto, Documento 14196/14, 20/10/2014.

90 Deben destacarse dos previsiones respecto del compromiso presentado por la UE: «la primera es que la reducción de las emisiones pretende ser únicamente doméstica, ya que se informa del compromiso de no utilizar mecanismos de mercado; la segunda se refiere al hecho de que la acción presentada se circunscribe únicamente al ámbito de la mitigación, sin que se haya incluido ninguna previsión respecto a adaptación». Giles Carnero, «La contribución...», 210. Dado que el Acuerdo de París ha fortalecido la adaptación como pilar clave de la política climática mundial, situándola al nivel de la mitigación, resulta llamativo que la UE se haya alejado del acuerdo en este ámbito. Beatriz Pérez de las Heras, «From Kyoto to Paris: The European Union's Contribution to a New World Climate Order», Revista Catalana de Dret Ambiental, vol. IX, n. ${ }^{\circ} 1$ (2018): 20.

${ }_{91}$ Naciones Unidas, «Decisión 1/CP.21 - Aprobación del Acuerdo de París», contenido en el Informe de la Conferencia de las Partes sobre su 21 er período de sesiones, celebrado en París del 30 de noviembre al 13 de diciembre de 2015 - Segunda parte: Medidas adoptadas por la Conferencia de las Partes en su 21er período de sesiones (FCCC/CP/2015/10/ Add.1), de 29 de enero de 2016. 
las obligaciones se aplican a todos los países firmantes del acuerdo, «pero su ritmo y grado de implementación se enmarca en el contexto del principio de responsabilidades comunes, pero diferenciadas, a la luz de las diferentes circunstancias nacionales» ${ }^{92}$.

El Acuerdo de Paris es considerado un buen acuerdo. Especialmente positivo se considera que países que hasta ese momento se mostraban reacios en esta cuestión, como EEUU o Rusia y últimamente Canadá o Japón, firmasen el acuerdo. En cierta manera, las negociaciones y el resultado de París consolidaron una tendencia que refleja «la construcción de una nueva idea de la arquitectura climática mundial», en la que cabe destacar «el paso a un liderazgo triangular - Unión Europea, Estados Unidos, BASIC-» y en la que se busca «atomizar los compromisos, especialmente en el sentido de la mitigación, y en menor medida, respecto del financiamiento ${ }^{93}$.

Puede parecer excesivo decir que «el Acuerdo de París de 2015 constituye un importante hito histórico en la lucha mundial contra el cambio climático», aunque es cierto que «es el primer acuerdo multilateral en materia de cambio climático que cubre la casi totalidad de las emisiones mundiales ${ }^{94}$. Evidentemente, es positivo que todos los países hayan consensuado y aceptado como vinculante el compromiso de limitar a $1,5^{\circ} \mathrm{C}$ el aumento de la temperatura para 2100, así como el compromiso de aplicar medidas de mitigación y de rendir cuentas de manera transparente, al objeto de poder hacer un seguimiento de los progresos. En este sentido, el acuerdo «ha resultado ser un punto de inflexión en el régimen internacional de cambio climático ya que establece obligaciones de reducción tanto para los países desarrollados como países en desarrollo» ${ }^{95}$.

No obstante, se deja un margen considerable a los países, que deben informar de los esfuerzos realizados pero sin que se establezcan objetivos cuantificados específicos, como los que fijó el Protocolo de Kioto ${ }^{96}$. Esa

92 Beatriz Pérez de las Heras, «La Unión Europea y el Acuerdo de París: liderando la acción global contra el cambio climático», Unión Europea Aranzadi, n. ${ }^{\circ} 11$ (2017): 50.

${ }_{93}$ María del Pilar Bueno Rubial, «El Acuerdo de París: ¿una nueva idea sobre la arquitectura climática internacional?», Relaciones Internacionales, . $^{\circ} 33$ (2016): 90-92.

${ }^{94}$ Comisión Europea, Comunicación de 2 de marzo de 2016, El camino desde París: evaluar las consecuencias del Acuerdo de París y complementar la propuesta de Decisión del Consejo relativa a la firma, en nombre de la Unión Europea, del Acuerdo de París adoptado en el marco de la Convención Marco de las Naciones Unidas sobre Cambio Climático, $\operatorname{COM}(2016) 110$ final, 2.

95 Mathieu Demares, «La importancia de la gobernanza climática global y de la vigésimo primera Conferencia de las Partes en la lucha contra el Cambio Climático», Observatorio Medioambiental, vol. 19 (2016): 68.

${ }_{96}$ Precisamente, la flexibilidad y discrecionalidad dejada a los países a la hora de implementar sus obligaciones climáticas «es probablemente una de las claves del éxito del Acuerdo de París». Pérez de las Heras, «La Unión Europea...», 49. Por el contrario, hay quien las ve 
doble vertiente permite afirmar que «la transición hacia un mundo hipocarbónico ha recibido un espaldarazo en París pero su velocidad y profundidad están aún por determinar» ${ }^{97}$. La Comisión subrayaba el impulso que el Acuerdo de París supone para la transición hacia una economía hipocarbónica y circular en el seno de las medidas propuestas para desarrollar dicha transición y que complementaban la Unión de la Energía ${ }^{98}$.

El Acuerdo de París debía entrar en vigor una vez que fuese ratificado por más de 55 países que sumen más del $55 \%$ de las emisiones globales de GEI. La ratificación del mismo por parte de la UE en octubre de 2016, supuso su entrada en vigor el 4 de noviembre de ese mismo año. Al mismo tiempo, la UE hacía pública las propuestas que llevaría a la COP 22, a celebrar en Marrakech ${ }^{99}$ y anunciaba que cumpliría su objetivo para 2020 (Kioto II), pues los niveles de emisión de GEI de 2014 confirmaban una reducción del $24 \%$ con respecto a los de 1990 y reiteraba su compromiso de continuar la aplicación de sus políticas climáticas.

A pesar de todo, la noticia de mayor calado en la Conferencia de Marrakech fue la victoria en las elecciones presidenciales de EEUU de Donald Trump, partidario de abandonar el Acuerdo de París. Ello provocó que los representantes de todos los países aprobasen una declaración de apoyo a dicho acuerdo ${ }^{100}$. La comunidad internacional volvió así a lanzar un mensaje de unidad, al reafirmar «de manera unánime la voluntad de defender el mencionado acuerdo, afirmando que la lucha contra el cambio climático es ya irreversible» ${ }^{101}$. Los países se han percatado del agotamiento de un modelo económico intensivo en emisiones de GEI que conlleva perjudiciales

como la razón por las que el Acuerdo de París «sigue descansando en la voluntad unilateral, incluso más que antes si cabe, de los Estados a la hora de contribuir al esfuerzo de mitigación», lo que «conduce a calificar como decepcionante el Acuerdo de París». Sergio Salinas Alcega, «El acuerdo de París de diciembre de 2015: la sustitución del multilateralismo por la multipolaridad en la cooperación climática internacional», Revista española de derecho internacional, vol. 70, n. ${ }^{\circ} 1$ (2018): 64.

97 Gonzalo Escribano Francés y Lara Lázaro Touza, «Energía y clima en 2016: en busca de una gobernanza policéntrica», Análisis del Real Instituto Elcano (ARI), 2016, n. ${ }^{\circ} 28$ (2016): 10.

98 Comisión Europea, Comunicación de 20 de julio de 2016, Acelerar la transición de Europa hacia una economía hipocarbónica, COM (2016) 500 final.

99 Consejo de la Unión Europea, Preparativos de las reuniones de la Convención Marco de las Naciones Unidas sobre Cambio Climático que se celebrarán en Marrakech - Conclusiones del Consejo, Documento 12807/16, 30/09/2016.

100 Marrakech action proclamation for our climate and sustainable development, publicado el 18 de noviembre de 2016 en la página web de la Convención Marco sobre Cambio Climático de NNUU, http://unfecc.int/files/meetings/marrakech_nov_2016/application/pdf/ marrakech_action_proclamation.pdf, acceso el 18 de noviembre de 2016.

101 Antxon Olabe Egaña, «Cambio climático en tiempos de incertidumbre», Política Exterior, vol. 31, n. 175 (2017): 116. 
consecuencias socioeconómicas y ambientales, al tiempo que aprecian las bondades de los compromisos climáticos ${ }^{102}$.

La unidad se mantuvo en la COP 23 celebrada en Bonn, donde se apoyó sin fisuras nuevamente el Acuerdo de París y los objetivos en él estableci$\operatorname{dos}^{103}$. La COP 24 que ha tenido lugar en Katowice (Polonia) ha adoptado el reglamento para aplicar el Acuerdo ${ }^{104}$. Sin embargo, no ha habido unanimidad sobre cómo actuar ante la constatación de un nuevo aumento de las emisiones de GEI ${ }^{105}$. La UE, arrastrando a China y a la mayoría de los países, ha defendido tomar como base científica para actuar el informe que el IPCC había presentado previamente ${ }^{106}$, en el que se insta a frenar con urgencia el aumento de la temperatura en $1,5^{\circ} \mathrm{C}$, mientras que países como EEUU, Rusia y Arabia Saudí se han mostrado incrédulos ante dicho documento.

\section{El paquete energía limpia}

A finales de 2016, la Comisión incidía en la necesidad de dar pasos en diferentes ámbitos para lograr un futuro europeo sostenible ${ }^{107}$, desarrollando dos líneas de trabajo. Por un lado, la integración plena de los objetivos de desarrollo sostenible en el marco político europeo; por otro, la puesta en marcha de un proceso de reflexión en la UE sobre las políticas sectoriales a partir de 2020 y

$102 \mathrm{Al}$ haber tomado conciencia «de la transición que se ha producido desde un sistema internacional de reparto de esfuerzos de mitigación, hacia una situación en la cual los países y las empresas compiten por las oportunidades derivadas de una economía baja en carbono». Gonzalo Escribano Francés y Lara Lázaro Touza, «Energía y clima en 2017: volatilidad contenida, implementación climática e incertidumbre política», Análisis del Real Instituto Elcano (ARI), n. ${ }^{\circ} 31$ (2017): 7.

103 Naciones Unidas, Preparations for the implementation of the Paris Agreement and the first session of the Conference of the Parties serving as the meeting of the Parties to the Paris Agreement (FCCC/CP/2017/10/L.13), de 18 de noviembre de 2017.

104 Sitio de la Conferencia de Katowice en la página web de la Convención Marco sobre Cambio Climático de NNUU, https://unfccc.int/es/katowice, acceso el 15 de diciembre de 2018.

105 Si bien entre 2014 y 2016, las emisiones mundiales de GEI se estancaron mientras el PIB mundial crecía, en 2017 volvieron a crecer un $1,6 \%$ y se prevé un aumento en 2018 del $2,7 \%$. El $60 \%$ de las emisiones están en manos de cuatro potencias, para tres de las cuales se prevén nuevos aumentos de emisiones el presente año: China las aumentará en el 4,7\%, EEUU en el 2,5\% y la India en el 6,3\%. Por el contrario, la UE las reducirá en el 0,7\%. Bruhwiler, L. et al, «Overview of the global carbón cycle», en Second State of the Carbon Cycle Report (SOCCR2): A Sustained Assessment Report, ed. por Cavallaro, N. et al (Washington: U.S. Global Change Research Program, 2018), 43.

106 Panel Intergubernamental sobre Cambio Climático (IPCC), Global Warming of $1.5^{\circ} \mathrm{C}$ (PNUMA, 2018), https://www.ipcc.ch/, acceso el 10 de diciembre de 2018.

107 Comisión Europea, Comunicación de 22 de noviembre de 2016, Próximas etapas para un futuro europeo sostenible. Acción europea para la sostenibilidad, COM (2016) 739 final. 
la aplicación de los objetivos de desarrollo sostenible a largo plazo. Entre las prioridades citadas destacan la aplicación efectiva de las medidas ambientales, así como las acciones sobre la Unión de la Energía y cambio climático.

Prácticamente al mismo tiempo, la Comisión presentó «el más ambicioso conjunto de propuestas en materia de energía limpia y transición a la economía hipocarbónica» ${ }^{108}$. El conocido como Paquete energía limpia contiene una serie de medidas en materia de energías renovables que incluye también el aumento de la eficiencia energética ${ }^{109}$. También tiene una vertiente referida a la seguridad energética, pues con esta propuesta, la UE «parece sustituir la estrategia geopolítica de reducir la dependencia europea de las importaciones de gas ruso por la de diversificar las fuentes energéticas hacia las renovables y reducir la dependencia de los combustibles fósiles, incluyendo el gas natural» ${ }^{110}$. El paquete incluye la elaboración de varios actos legislativos entre los que destacan el Reglamento sobre la Gobernanza de la Energía, la Directiva sobre Energías Renovables y la Directiva de Eficiencia Energética ${ }^{111}$. Los objetivos de las medidas energéticas que comprende el paquete consisten en anteponer la eficiencia energética, lograr el liderazgo mundial en materia de energías renovables y ofrecer un trato justo a los consumidores (en materia de precios).

La idea de anteponer la eficiencia energética significa admitir que la energía más barata y limpia es la que no necesita ser producida o utilizada. Para ello se revisó el objetivo de eficiencia energética vinculante a escala de la UE para 2030 (tal y como se preveía en el Marco clima y energía), subiéndolo del $27 \%$ al $30 \%$, posibilitando así alcanzar los objetivos en materia de reducción de emisiones de GEI. Esta decisión sigue mostrando «la visibili-

108 Dionisio Fernández de Gatta Sánchez, «Unión Europea: inicio del debate sobre la transición energética», en Observatorio de Políticas Ambientales 2017, coord. por Fernando López Ramón (Madrid: CIEMAT, 2017), 59.

${ }^{109}$ Comisión Europea, Comunicación de 30 de noviembre de 2016, Energía limpia para todos los europeos, COM (2016) 860 final.

110 Escribano y Lázaro, «Energía y clima en 2017...», 9. La relevancia del gas natural se debe a que, «en un escenario de descarbonización avanzada, el gas es el único combustible fósil concebido como energía de transición», de manera que en el conjunto de la UE «el uso del gas contribuirá a una retirada ordenada del carbón del mix de generación eléctrica y de los sistemas de generación de calor, ya que no siempre estarán disponibles de forma coste-eficiente las alternativas renovables». Antxon Olabe, Mikel González-Eguino y Teresa Ribera, «Hacia un nuevo orden mundial de la energía», Documento de Trabajo del Real Instituto Elcano, n. ${ }^{\circ} 12$ (2017): 17-18. Posibles escenarios de diversificación de fuentes de gas podrían ser las conexiones con el mar Caspio y el Magreb. Gutiérrez, «La Unión de la Energía...», 924-927.

111 «El conjunto legislativo propuesto cubre el $90 \%$ de las medidas propuestas en la Estrategia Marco para la Unión de la Energía presentada en 2015». Antonio López-Nicolás Baza, «El liderazgo de la Unión Europea en Energías Renovables: el paquete de Energía Limpia de la Comisión Europea», Cuadernos de Energía, n. ${ }^{\circ} 55$ (2018): 22. 
dad e importancia que la UE le ha dado a la transición energética (ante los retos geopolíticos y climáticos del siglo XXI) y en el marco de ésta, al factor eficiencia energética», al considerarla «como el primer combustible» y promoverla «como la principal fuente de energía latente en el seno de la UE» ${ }^{112}$.

El objetivo de convertir a la UE en líder mundial en materia de energías renovables se quiere materializar en 2030, logrando que la electricidad renovable represente la mitad de la combinación de producción eléctrica de la UE. En lo que respecta a la energía eólica, la UE ya era líder en el momento de presentar la comunicación. También la energía solar fotovoltaica es un sector puntero en Europa pero se reconoce la necesidad de aumentar su capacidad de fabricación. En cuanto a la biomasa sólida para producir calor y electricidad, es considerado un sector respetuoso con el clima pero, al objeto de limitar presiones adicionales sobre los bosques, se reclama una gestión sostenible de los mismos y buscar sinergias con la economía circular. Todo ello queda englobado en el objetivo, también previsto en el Marco energía y clima para 2030 de llegar, en dicho año, al menos al $27 \%$ de cuota de energías renovables consumidas en la UE. Precisamente, el mantenimiento de este porcentaje, frente al aumento del anterior, referido a la eficiencia energética, fue criticado por considerarlo insuficiente para reducir la dependencia energética europea y porque su aumento, también al $30 \%$, hubiese sido mejor para la competitividad ${ }^{113}$.

En febrero de 2017 la Comisión presentó un informe sobre la situación de las energías renovables en la UE ${ }^{114}$. Destacaba positivamente el importante papel que las mismas desempeñan ya en la seguridad energética, no en vano la cuota de las fuentes de energías renovables había alcanzado en 2014 el $16 \%$ del consumo final bruto de energía. La estimación para 2015 era del $16,4 \%$-que finalmente fue del $16,7 \%$, tal y como ya se ha dicho arriba ${ }^{115}$ - pero se subrayaba la necesidad de intensificar los esfuerzos para mantener la tendencia y cumplir con el objetivo previsto para 2030 de una cuota del $27 \%$. Para ello, pocos días después, la Comisión ponía en marcha el proceso para aprobar una nueva Directiva de energías renovables presentando su propuesta específica al respecto ${ }^{116}$. La impor-

112 Herrero, «La seguridad energética...», 94-95.

113 Fundación Energías Renovables, ed. Directiva Europea sobre Energías Renovables. Desafíos y oportunidades (Madrid: FER, 2017), acceso el 5 de octubre de 2018, www fundacionrenovables.org, 5 .

114 Comisión Europa, Documento de 1 de febrero de 2017, Informe de situación en materia de energías renovables, COM (2017) 57 final.

115 Comisión Europea, Third Report..., 3.

116 Comisión Europea, Documento de 23 de febrero de 2017, Propuesta de Directiva relativa al fomento del uso de energía procedente de fuentes renovables (refundición), COM (2016) 767 final. 
tancia de la misma es fundamental, no en vano «es considerada clave para el crecimiento económico, la creación de empleo y mejorar la seguridad energética de la Unión, y es el principal instrumento para asegurar que los Estados miembros cumplan con el objetivo de aumentar en un $20 \%$ la producción de renovables en 2020 y para que se reduzcan los GEI»117.

El texto de la Directiva propuesta por la Comisión «fija un objetivo vinculante para la UE en relación con la cuota de energía procedente de fuentes renovables en el consumo final bruto de energía en 2030» (art. 1). Especifica que por dichas fuentes de energía se entenderá las «renovables no fósiles, es decir, energía eólica, energía solar (solar térmica y solar fotovoltaica) y energía geotérmica, calor ambiente, mareomotriz, undimotriz y otros tipos de energía oceánica, hidráulica, biomasa, gases de vertedero, gases de plantas de depuración y biogás» (art. 2). Y, siguiendo lo establecido en el Marco energía y clima para 2030, se establece como objetivo global vinculante de la UE que «los Estados miembros velarán conjuntamente por que la cuota de energía procedente de fuentes renovables sea de al menos el $27 \%$ del consumo final bruto de energía de la UE en 2030» (art. 3).

El mantenimiento de dicha cuota en el $27 \%$ fue una de las mayores criticas lanzadas desde el $\mathrm{PE}^{118}$, junto con el hecho de no incluir obligaciones específicas para cada uno de los Estados miembros. Ello ha alargado las negociaciones durante la tramitación del texto por medio del procedimiento legislativo ordinario, más aún tras las enmiendas aprobadas por el PE, pues aumentaba su nivel de exigencia hasta una cuota del $35 \%$ y requería el establecimiento de objetivos nacionales ${ }^{119}$. Finalmente, en junio de 2018 el PE, la Comisión y los Gobiernos de los Estados miembros llegaron al acuerdo, confirmado por el Consejo, de fijar como objetivo principal de la Directiva el logro en 2030 de una cuota del $32 \%$ de la energía procedente de fuentes renovables ${ }^{120}$.

117 Xira Ruiz Campillo, «Transformación de la UE en su lucha contra el cambio climático», Economía Exterior, n. ${ }^{\circ} 81$ (2017): 87.

118 Ya se ha mencionado en la nota 63 que ante el Marco energía y clima para 2030 el PE reclamó una cuota de al menos el $30 \%$, algo que repitió ante el informe de la Comisión sobre la situación de las energías renovables. Parlamento Europeo, Resolución de 23 de junio de 2016, sobre el informe de situación en materia de energías renovables (2016/2041 (INI). DOUE C 91, de 9 de marzo de 2018, 21.

119 Enmiendas aprobadas por el Parlamento Europeo, el 17 de enero de 2018, sobre la propuesta de Directiva del Parlamento Europeo y del Consejo relativa al fomento del uso de energía procedente de fuentes renovables (refundición) (COM (2016) 0767 - C8-0500/20162016/0382 (COD)), enmienda 324.

${ }^{120}$ Consejo de la UE, Comunicado de prensa del 27 de junio de 2018, Energías renovables: el Consejo confirma el acuerdo alcanzado con el Parlamento Europeo, 417/18. 
Al mismo tiempo, se lograba el acuerdo en torno al Reglamento relativo a la gobernanza de la Unión de la Energía, en el que sí se prevén planes nacionales en materia de clima y energía para cada una de las dimensiones de la misma. Se obligaría, así, a los Estados miembros a diseñar una estrategia energética y climática con objetivos nacionales, contribuciones, políticas y medidas para el 31 de diciembre de 2019 y cada diez años desde esa fecha. Además, se estableció el calendario para el logro del $32 \%$ de energías renovables para 2030, de manera que la UE deberá haber alcanzado el $18 \%$ del objetivo en 2022 , el $43 \%$ en 2025 y el $65 \%$ en $2027^{121}$.

También en el ámbito de la eficiencia energética, y por iniciativa del $\mathrm{PE}$, se va a aumentar el porcentaje de mejora de la eficiencia energética para 2030. En este caso, en la tramitación de la Directiva de eficiencia energética, el PE propuso aumentar el porcentaje de eficiencia energética al $34 \%$ para 2030, ante lo que el Consejo acabó aceptando que se comprometería a una cuota mayor del $30 \%$. Tras nuevas negociaciones interinstitucionales, el PE propuso una porcentaje mínimo del 32,5\% (art. 1 de la propuesta de Directiva) ${ }^{123}$. Tanto la propuesta de este acto, como la de los otros dos mencionados, incluyendo la modificación de los objetivos, fue aprobada por el PE en sesión plenaria el 13 de noviembre de 2018.

Establecidos los actos legislativos del paquete de medidas para el periodo hasta 2030 y teniendo en cuenta los preocupantes datos de emisiones globales previstas para 2018, así como las recomendaciones del IPCC para frenar el aumento de la temperatura en $1,5^{\circ} \mathrm{C}$, la Comisión hizo pública su propuesta para que las emisiones de GEI desaparezcan en Europa para $2050^{124}$. Se trata de una visión que permita a la UE ir más allá de los objetivos de clima y energía previstos, desarrollando políticas que posibiliten dejar de lado los combustibles fósiles para $2050^{125}$. La Comisión constata

121 Consejo de la UE, Comunicado de prensa del 29 de junio de 2018, Gobernanza de la Unión de la Energía: el Consejo confirma el acuerdo alcanzado con el Parlamento Europeo, $424 / 18$

122 Consejo de la UE, Documento 9287/18, Proposal for a Directive of the European Parliament and of the Council amending 2012/27/EU on energy efficiency. Bruselas, 4 de junio de 2018.

${ }^{123}$ Parlamento Europeo, Provisional Agreement Resulting from Interinstitutional Negotiations - Proposal for a directive of the European Parliament and of the Council amending 2012/27/EU on energy efficiency (COM(20160761 - C8-0498/2016- 2016/0376(COD)), 17 de julio de 2018. Acceso el 5 de noviembre de 2018, www.europarl.europa.eu.

${ }^{124}$ Comisión Europea, Comunicación de 28 de noviembre de 2018, A Clean Planet for all. A European strategic long-term visión for a prosperous, modern, competitive and climate neutral economy, COM (2018) 773 final.

125 «La finalidad de esta estrategia a largo plazo no es tanto establecer objetivos, sino crear una visión y una dirección adecuada, trazar un plan para ello, e inspirar y permitir a las 
que el paquete 2030 permitirá una reducción de emisiones de GEI del $45 \%$ para 2030 (por encima del $40 \%$ previsto como objetivo) y llegar al $60 \%$ en 2050. Sin embargo, ello no sería suficiente para cumplir con el Acuerdo de París por lo que la Comisión, tras evaluar las vías para ello, concluye que la UE puede adoptar las medidas para lograr reducir las emisiones entre el $80 \%$ y el $100 \%$ (en comparación con 1990) pudiendo, por tanto, llegar a una situación de cero emisiones para 2050.

La Comisión recuerda que entre 1990 y 2016 las emisiones de GEI de la UE se redujeron en el $22 \%$ mientras el PIB creció un $54 \%$. Como se ve, los impactos económicos totales son positivos a pesar de las importantes inversiones adicionales que requieren. Así, se prevé un incremento adicional del PIB del $2 \%$ con las políticas de descarbonización que deben conducir al objetivo de emisiones cero, además del beneficio económico que supondrá la erradicación de los daños económicos ocasionados por el cambio climático.

Finalmente, según la propuesta de la Comisión, el camino hacia una economía climáticamente neutra exigirá una acción conjunta en siete ámbitos estratégicos: eficiencia energética; despliegue de energías renovables; movilidad limpia, segura y conectada; industria competitiva y economía circular; infraestructuras e interconexiones; bioeconomía y sumideros naturales de carbono; captura y almacenamiento de carbono para hacer frente a las emisiones restantes. A destacar la propuesta en el sector de la energía, consistente en que en 2050 más del $80 \%$ de la electricidad de la UE se produzca a partir de fuentes de energía renovable.

\section{Conclusiones}

Ante la falta de una regulación contenida en los Tratados originarios, han sido los Tratados modificativos los que han ido configurando la política medioambiental europea. Los dos avances más relevantes han venido determinados por la vinculación del crecimiento económico a la protección medioambiental, estableciendo así el desarrollo sostenible como objetivo fundamental de la UE, y por la integración de dicho objetivo en la definición y en la realización de las demás políticas y acciones.

El mayor reto medioambiental en la actualidad es el cambio climático, y la lucha contra el mismo ha ido copando mayor presencia tanto en el de-

partes interesadas, investigadores, empresarios y ciudadanos por igual desarrollar nuevas e innovadoras industrias, empresas y empleos asociados». Comisión Europea, Comunicado de prensa de 28 de noviembre de 2018, La Comisión aboga por una Europa climáticamente neutra de aquí a 2050, IP/18/6543. 
sarrollo de las diferentes políticas europeas como en la acción exterior de la UE, lo que ha convertido a Europa en la potencia económica del planeta con el mayor compromiso medioambiental y con las propuestas más avanzadas en la lucha contra el calentamiento global. A este respecto, debe subrayarse el esfuerzo europeo por lograr un acuerdo internacional que sustituya al Protocolo de Kioto y que el Acuerdo de París ha sido posible en buena medida gracias al impulso de la UE.

Las propuestas europeas más notorias a favor de la acción climática están posibilitando a la UE posicionarse adecuadamente para hacer frente al reto de la seguridad de abastecimiento energético. En efecto, la apuesta por las energías procedentes de fuentes renovables es una vía de acción que la UE está impulsando significativamente los últimos años. Ahora bien, se trata de una cuestión en la que se evidencian en mayor medida las sensibilidades dispares de los Estados miembros, así como una postura reacia por parte de éstos a ceder soberanía en materia energética. Precisamente, la acción climática europea sirve de ejemplo para demostrar que desarrollar una perspectiva europea, también en materia energética, puede otorgar mayores beneficios que mantener una perspectiva gubernamental o nacional. Incluso en el ámbito exterior, actuar con una sola voz tal y como hace la UE en las negociaciones climáticas, posibilitaría unos mejores resultados en las conversaciones con países proveedores de energía y mejorar la situación de dependencia.

La estrategia de la Unión de la Energía, que engloba tanto el Marco clima y energía para 2030 como la Estrategia sobre Seguridad Energética, y que se está desarrollando por medio del paquete energía limpia, delimita el camino que piensa seguir la UE en los próximos años, a saber, impulsar una transición energética que favorezca el logro del desarrollo sostenible. Es cierto que es posible exigir a la UE mayores esfuerzos y propuestas más ambiciosas pero resulta necesario reconocer que los objetivos actualmente establecidos tienen la particularidad de combinar lo deseable con lo posible. En este sentido, la relevancia del paso dado evolucionando el objetivo 40/27/27 a objetivo 40/32/32,5 es evidente y su consecución en 2030 es factible dadas las capacidades de la UE. Se trata de la aspiración mínima que Europa debe mostrar para avanzar hacia una economía sostenible y hacer frente de manera exitosa a los retos de la seguridad energética y el cambio climático, incluyendo los compromisos del Acuerdo de París. La asunción por parte del Consejo Europeo de la propuesta de la Comisión consistente en llegar a cero emisiones en 2050 e implementar un paquete de medidas para su logro a aplicar en el periodo 2030-2050 acabará de situar a la UE en la posición idónea para hacer frente a los retos mencionados. 


\section{Sobre el autor}

Asier García Lupiola es Doctor en Derecho (UPV-EHU), Diploma de Estudios Avanzados en Unión Europea (UNED), Master en Estudios Europeos (Universidad de Deusto) y Especialista en Relaciones Internacionales (UPV-EHU). Es profesor agregado (profesor contratado doctor) en la UPVEHU, imparte las asignaturas Economía Contemporánea y Comercio Exterior en la Facultad de Economía y Empresa y Unión Europea en las Aulas de la Experiencia. Sexenio de investigación reconocido por la CNEAI. Sus líneas de investigación sobre la UE son, por un lado, el sistema institucional y el proceso normativo, por otro, la política medioambiental y la acción climática.

\section{About the Author}

Asier García Lupiola is a PhD in Law (UPV-EHU), Advanced Diploma on Advanced Studies in European Union (UNED), Master in European Studies (Universidad de Deusto) and Specialist in International Relations (UPV-EHU). Professor at the Faculty of Economics and Business (UPV-EHU), teaches the subjects Contemporary Economics, International Trade and European Union. Research activity recognized by CNEAI. His lines of research on the European Union are, on the one hand, the institutional system and the legislation process, on the other, environmental policy and climate action. 


\section{Derechos de autor}

Los derechos de autor (para la distribución, comunicación pública, reproducción e inclusión en bases de datos de indexación y repositorios institucionales) de esta publicación (Cuadernos Europeos de Deusto, CED) pertenecen a la editorial Universidad de Deusto. El acceso al contenido digital de cualquier número de Cuadernos Europeos de Deusto es gratuito inmediatamente después de su publicación. Los trabajos podrán leerse, descargarse, copiar y difundir en cualquier medio sin fines comerciales y según lo previsto por la ley; sin la previa autorización de la Editorial (Universidad de Deusto) o el autor. Así mismo, los trabajos editados en CED pueden ser publicados con posterioridad en otros medios o revistas, siempre que el autor indique con claridad y en la primera nota a pie de página que el trabajo se publicó por primera vez en CED, con indicación del número, año, páginas y DOI (si procede). Cualquier otro uso de su contenido en cualquier medio o formato, ahora conocido o desarrollado en el futuro, requiere el permiso previo por escrito del titular de los derechos de autor.

\section{Copyright}

Copyright (for distribution, public communication, reproduction and inclusion in indexation databases and institutional repositories) of this publication (Cuadernos Europeos de Deusto, CED) belongs to the publisher University of Deusto. Access to the digital content of any Issue of Cuadernos Europeos de Deusto is free upon its publication. The content can be read, downloaded, copied, and distributed freely in any medium only for non-commercial purposes and in accordance with any applicable copyright legislation, without prior permission from the copyright holder (University of Deusto) or the author. Thus, the content of CED can be subsequently published in other media or journals, as long as the author clearly indicates in the first footnote that the work was published in CED for the first time, indicating the Issue number, year, pages, and DOI (if applicable). Any other use of its content in any medium or format, now known or developed in the future, requires prior written permission of the copyright holder. 